NBER WORKING PAPER SERIES

\title{
HOW FAST DO PERSONAL COMPUTERS DEPRECIATE? CONCEPTS AND NEW ESTIMATES
}

\author{
Wendy E. Dunn \\ Mark E. Doms \\ Stephen D. Oliner \\ Daniel E. Sichel \\ Working Paper 10521 \\ http://www.nber.org/papers/w10521 \\ NATIONAL BUREAU OF ECONOMIC RESEARCH \\ 1050 Massachusetts Avenue \\ Cambridge, MA 02138 \\ May 2004
}

Forthcoming in Tax Policy and the Economy, edited by James Poterba, MIT Press. We wish to thank Ana Aizcorbe, Barbara Fraumeni, Jane Gravelle, Michael Kiley, Brent Moulton, Jim Poterba, and Brian Sliker for helpful comments on an earlier draft of the paper. We also thank Chuck Hulten, Dale Jorgenson, and Nick Oulton for useful discussions concerning the measurement of capital. Michael Hurlbut, Robert Little, and Brian Rowe provided excellent research assistance. The views expressed in the paper are those of the authors and should not be attributed to the Federal Reserve Board, the Federal Reserve Bank of San Francisco, or other staff at either institution. The views expressed herein are those of the author(s) and not necessarily those of the National Bureau of Economic Research.

(C2004 by Wendy E. Dunn, Mark E. Doms, Stephen D. Oliner, and Daniel E. Sichel. All rights reserved. Short sections of text, not to exceed two paragraphs, may be quoted without explicit permission provided that full credit, including (C) notice, is given to the source. 
How Fast Do Personal Computers Depreciate? Concepts and New Estimates

Wendy E. Dunn, Mark E. Doms, Stephen D. Oliner, and Daniel E. Sichel

NBER Working Paper No. 10521

May 2004

JEL No. O47

\section{$\underline{\text { ABSTRACT }}$}

This paper provides new estimates of depreciation rates for personal computers using an extensive database of prices of used PCs. Our results show that PCs lose roughly half their remaining value, on average, with each additional year of use. We decompose that decline into age-related depreciation and a revaluation effect, where the latter effect is driven by the steep ongoing drop in the constant-quality prices of newly-introduced PCs. Our results are directly applicable for measuring the depreciation of PCs in the National Income and Product Accounts (NIPAs) and were incorporated into the December 2003 comprehensive NIPA revision. Regarding tax policy, our estimates suggest that the current tax depreciation schedule for PCs closely tracks the actual loss of value in a zero-inflation environment. However, because the tax code is not indexed for inflation, the tax allowances would be too small in present value for inflation rates above the very low level now prevailing.

Mark E. Doms

San Francisco Federal Reserve Bank

101 Market Street, MS \#1130

San Francisco, CA 94105-1530

Wendy E. Dunn

Federal Reserve Board, MS \#82

$20^{\text {th }}$ and Constitution Ave., NW

Washington, DC 20551
Stephen D. Oliner

Federal Reserve Board, MS \#66

$20^{\text {th }}$ and Constitution Ave., NW

Washington, DC 20551

stephen.d.oliner@frb.gov

Daniel E. Sichel

Federal Reserve Board, MS \#89

$20^{\text {th }}$ and Constitution Ave., NW

Washington, DC 20551

dan.sichel@frb.gov 


\section{INTRODUCTION}

The measurement of depreciation is a complex - and, to some, obscure - area of economics. However, getting the numbers right is critical for important issues in tax policy and capital measurement. This is particularly true for computers and other high-tech capital goods, which have assumed an increasingly central role in U.S. business activity over the past decade. In this regard, the recent debate about the contribution of information technology to economic growth has focused attention on the measurement of high-tech capital goods and, consequently, on the rate at which they depreciate.

Over the years, economists have devoted considerable attention to the measurement of depreciation. Notable early studies include Griliches (1960) - who estimated depreciation rates for farm tractors - and Hall's (1971) work on pickup trucks. ${ }^{1}$ Somewhat later, Hulten and Wykoff (1981a, 1981b) estimated depreciation rates for many different types of equipment and structures, and the Bureau of Economic Analysis (BEA) has adopted their figures for use in the U.S. National Income and Product Accounts (NIPAs).

For high-tech assets, however, the literature on depreciation is remarkably thin given their importance in the economy. Hulten and Wykoff's pioneering research predated the explosion in demand for information technology capital; thus, their studies did not include computing equipment, and they treated quality change in a relatively limited way. Oliner (1993, 1994) estimated depreciation rates for mainframe computers and computer peripheral equipment, but these results are somewhat dated at this point, and there has been no follow-up research for these assets. To our knowledge, only two prior studies - Geske, Ramey, and Shapiro (2003) and

\footnotetext{
${ }^{1}$ See Jorgenson (1974) for an excellent overview of this early literature, along with Fraumeni (1997) and Jorgenson
} (1996) for more recent surveys of the literature. 
Wykoff (2003) - have estimated depreciation for personal computers. Wykoff's paper, though, mainly concerns methodology, and his empirical work uses a very small sample of computer prices merely to illustrate his approach. Geske, Ramey, and Shapiro have a richer dataset, which they employ to estimate depreciation for PCs and to highlight the role of obsolescence in driving depreciation for these assets.

Our paper builds on the work of Geske, Ramey, and Shapiro to further narrow the knowledge gap surrounding depreciation rates for PCs. Like their work - and most of the earlier literature - we rely on prices of used assets to estimate depreciation. We construct a large dataset of prices and model characteristics for used PCs listed in bluebooks. This dataset includes nearly 13,000 observations and spans the period from 1985 to 2002, covering almost the entire era of personal computers.

With these data in hand, we followed the empirical approach in Oliner $(1993,1994)$, which regressed used asset prices on product characteristics and functions of age and time. This approach - which relates closely to Hall's (1971) framework - effectively adds age to a standard hedonic price regression. This framework allows us to decompose the total decline in PC prices into two parts. The first is the revaluation of existing units over time as new models are introduced at lower constant-quality prices. The second part is the decline in a PC's value as it ages because of reduced efficiency and eventual scrappage; although PCs suffer some wear-andtear, we believe that this aging effect mainly arises because older PCs become unable to run the latest software or lack features (like a CD-ROM drive) that come to be considered standard. As discussed in the next section, these two components of price change - depreciation and revaluation - have direct applications to tax policy and capital measurement. 
Not surprisingly, our empirical results indicate that PCs lose value at a rapid pace. Over our full sample period, the value of a PC declines roughly 50 percent, on average, with each year of use, implying that a newly-installed PC can be expected to be nearly worthless after five or six years of service. In addition, our results suggest that both depreciation and revaluation contribute to the sharp drop in the value of installed PCs, though revaluation plays the dominant role, especially in the early years of a PC's life.

Our results have important implications for tax policy and for the measurement of depreciation and capital stocks in the NIPAs. Regarding tax policy, we show that in a world with changing relative prices, firms should be permitted to deduct both the age-related decline in an asset's value (i.e., depreciation) and the revaluation of that asset relative to the general price level. The combined effect of depreciation and real revaluation measures the asset's real loss of value. Allowing firms to deduct this loss of value equalizes the effective tax rate across assets, a standard prescription for capital taxation. We then evaluate the current tax rules for depreciating PCs against this benchmark. The Internal Revenue Code permits firms to depreciate PCs and other computing equipment over a five-year service life, with annual deductions that equal or exceed 40 percent of the undepreciated value. Our results indicate that these tax allowances closely approximate the real loss of value that PCs experience when general price inflation is very low; however, because the tax code is not indexed for inflation, higher rates of inflation induce some distortions.

Turning to capital measurement, our preferred specification generates a non-geometric schedule of depreciation that averages about 22 percent annually over the first five years of a PC's service life. However, this schedule cannot be applied directly to the NIPAs. The 
difficulty arises because the constant-quality PC prices generated by our dataset trend down more rapidly than the corresponding NIPA price series, which relies on the producer price index for PCs. As we will show, the combined effect of depreciation and constant-quality price change is tightly pinned down in our dataset, which means that altering the rate of constant-quality price decline implies an opposite change in the measured rate of depreciation. To generate a depreciation schedule that is suitable for use in the NIPAs, we estimate a version of our regression that constrains the path for constant-quality prices to conform with the NIPA series. When we do this, the estimated depreciation rate rises to an average annual pace slightly above 34 percent.

This paper is organized as follows. The next section provides a conceptual discussion of depreciation. We highlight the concepts that are appropriate for tax policy and for capital accounting and then link these concepts to our empirical framework. Section 3 describes our data, and section 4 presents the empirical results, including a comparison to those in Geske, Ramey, and Shapiro (2003). Section 5 draws out the implications of our results for tax policy and for capital measurement. Conclusions are presented in the final section.

\section{MEASUREMENT OF DEPRECIATION, USER COST, AND CAPITAL STOCKS}

The literature on measuring capital is vast, complex, and often confusing. This section summarizes - with a minimum of technical detail - the concepts that guide our empirical work. We discuss the measures of depreciation that are relevant for tax policy, for constructing the user cost of capital, and for calculating capital stocks and capital consumption allowances in the 
NIPAs. For broader overviews of the literature on capital measurement, see Diewert (2002) and OECD (2001).

\section{Background}

As the starting point for our discussion, let $p_{z, t, a}^{k}$ denote the price of a capital good of type $k$ that has the set of embodied characteristics $z$. For a personal computer, $z$ would specify the speed of the processor, the size of the hard drive, the amount of memory, and so on. The other subscripts on $p$ indicate that the price is observed at time $t$ for a unit that is $a$ years old. One year later, when time has moved forward to $t+1$ and the unit is $a+1$ years old, the price becomes $p_{z, t+1, a+1}^{k}$, and the percentage decline in the asset's price over the year can be written

as:

$$
1-\frac{p_{z, t+1, a+1}^{k}}{p_{z, t, a}^{k}}=1-\left(\frac{p_{z, t+1, a+1}^{k}}{p_{z, t+1, a}^{k}} \times \frac{p_{z, t+1, a}^{k}}{p_{z, t, a}^{k}}\right)
$$

The first term in parenthesis compares the price of an $(a+1)$-year-old unit with an $a$-year-old unit at a fixed point in time. We denote this price ratio by $1-\delta^{k}$, where $\delta^{k}$ is the depreciation in asset value from an additional year of age. The second term compares the price of an $a$-year-old unit at times $t$ and $t+1$. We denote this second price ratio by $1+\pi^{k}$, where $\pi^{k}$ represents the 
percentage change in asset value between $t$ and $t+1$, with age held fixed. ${ }^{2}$ If we substitute $1-\delta^{k}$ and $1+\pi^{k}$ into equation 1 , we obtain

$$
1-\frac{p_{z, t+1, a+1}^{k}}{p_{z, t, a}^{k}}=1-\left(1-\delta^{k}\right)\left(1+\pi^{k}\right) \approx \delta^{k}-\pi^{k}
$$

where the final expression omits the cross-product, $\delta^{k} \pi^{k}$, which is small compared to $\delta^{k}$ and $\pi^{k}$.

It is important to note that the two components of price change in equation $2, \delta^{k}$ and $\pi^{k}$, are measured conditional on a fixed set of performance characteristics, $z$. This is evident from the notation on the left side of equation 2, which shows that $z$ does not vary as time and age each move forward by one year. Thus, the time-related element of the price change, $\pi^{k}$, represents the change in price holding quality fixed, which makes $\pi^{k}$ a constant-quality price measure. For personal computers, constant-quality prices have trended down at a rapid rate, owing in large part to advances in semiconductor chip technology. Under standard assumptions of competitive equilibrium, each introduction of a more powerful model at a lower constant-quality price forces down the prices of older models. $\pi^{k}$ captures this ongoing revaluation. The age-related element in the equation, $\delta^{k}$, measures the additional decline in asset value that stems from wear-and-tear, reductions in the efficiency of older models, and the approach of the asset's retirement. To avoid double-counting, $\delta^{k}$ cannot include the revaluation effect as well.

\footnotetext{
${ }^{2}$ By writing $\delta^{k}$ and $\pi^{k}$ without subscripts we have implicitly assumed that both dimensions of price change are constant. We have done this only to simplify the notation; the entire discussion would remain valid if we allowed $\delta^{k}$ and $\pi^{k}$ to vary with age and time.
} 
To illustrate these points, consider the following example involving PCs. Assume that the price of a new PC is $\$ 1000$ every year and that the value of a PC drops 45 percent over the course of a year (the value is $\$ 550$ after one year, $\$ 302.50$ after two years, and so on). The combined effect of depreciation and revaluation, $\delta^{k}-\pi^{k}$, is 45 percent in this example. Now, to allocate this loss of value between $\delta^{k}$ and $\pi^{k}$, assume that the quality of new PCs increases 25 percent each year. Given the fixed $\$ 1000$ price of a new PC, the 25 percent annual increase in quality implies that new PC prices drop 25 percent per year in constant-quality terms; in a competitive equilibrium, the prices of existing models will be pushed down by the same amount. Thus, $\pi^{k}$ (which captures this revaluation effect) would equal negative 25 percent, while $\delta^{k}$ (which represents the annual loss of value over and above the revaluation effect) would be 20 percent. For personal computers, $\delta^{k}$ largely reflects the influence of obsolescence rather than physical decay. Even units that continue to function like new will lose value as they age because they become too slow to perform some tasks efficiently, can no longer run the latest software, or lack features that come to be considered essential.

The literature on capital measurement has used a variety of terms to describe $\delta^{k}$ and $\pi^{k}$, as shown in table 1. Consistent with our discussion, Fraumeni (1997) labeled $\delta^{k}$ as depreciation, $\pi^{k}$ as the revaluation term, and $\delta^{k}-\pi^{k}$ as the combined effect of depreciation and revaluation. A number of other terms can be found in the literature for each of these concepts. One could make a case for each of these differing sets of terms, but we will use "depreciation" and "revaluation," which strike us as the most intuitive among the alternatives. 


\section{User Cost of Capital}

Depreciation and revaluation are important elements of the user cost of capital, which measures the implicit cost of using a capital good for a given period of time. The user cost is the equivalent of the "wage rate" for capital, and as such, it plays a key role in a wide range of economic analyses, including studies of business investment, tax policy, and productivity growth. ${ }^{3}$ Using a capital good for a given period generates two types of costs. The first is the cost of financing the acquisition of the capital good. Assuming that the purchase is debt financed (a very similar analysis would hold for equity financing), this cost equals the prevailing interest rate $(i)$ multiplied by the purchase price of the capital good. The second cost is the change in the value of the capital good over the period of use, which - as discussed above equals the combined effect of depreciation and revaluation $\left[p^{k}\left(\delta^{k}-\pi^{k}\right)\right]$.

The user cost of capital also reflects several key features of the tax code. As described by Hall and Jorgenson (1967), these tax parameters include the statutory tax rate on corporate profits (which we denote by $\tau$ ), the present value of the depreciation deductions for capital goods of type $k$ (denoted by $x^{k}$ ), and any investment tax credit for such capital goods (denoted by $\theta^{k}$ ). Given these tax parameters, we show in the appendix that the user cost of capital can be written as:

$$
c_{z, t, a}^{k}=\frac{1-\theta^{k}-\tau x^{k}}{1-\tau} p_{z, t, a}^{k}\left(i+\delta^{k}-\pi^{k}\right)=\frac{1-\theta^{k}-\tau x^{k}}{1-\tau} p_{z, t, a}^{k}\left[(i-\pi)+\delta^{k}-\left(\pi^{k}-\pi\right)\right]
$$

\footnotetext{
${ }^{3}$ See Hall and Jorgenson (1967) for the classic discussion of the user cost of capital.
} 
where the final part of the equation adds and subtracts the aggregate rate of inflation, $\pi$, to express the interest rate and the revaluation effect in real terms. As would be expected, equation 3 indicates that a larger investment tax credit and more accelerated depreciation allowances act to reduce the cost of capital. Equation 3 will prove useful in our discussion of the appropriate tax allowances for depreciation, to which we now turn.

\section{Tax Deductions for Depreciation}

The U.S. tax code allows businesses to deduct depreciation expenses when figuring their taxable income. These deductions influence the after-tax cost of investing in plant and equipment, and thus affect both the overall size and composition of the business capital stock. When designing tax rules for depreciation, a standard prescription is to equalize the effective tax rate across assets, so as to avoid distorting the composition of the capital stock.

Numerous studies have shown that effective tax rates can be equalized by setting tax allowances for depreciation to match the actual decline in the asset's value. ${ }^{4}$ In the appendix, we derive the implications of this rule when we allow for price inflation in the economy's aggregate basket of goods and services $(\pi)$ and asset revaluation relative to this aggregate price index $\left(\pi^{k}-\right.$

$\pi)$. As we show, the implied tax allowance is:

$$
D T A X_{z, t, a}^{k}=p_{z, t, a}^{k}\left[\delta^{k}-\left(\pi^{k}-\pi\right)\right]=p_{z, t, a}^{k}\left(\delta^{k}-\pi^{k}\right)+p_{z, t, a}^{k} \pi
$$

\footnotetext{
${ }^{4}$ See Gravelle $(1982,1994)$ for a derivation of this result, Bradford and Fullerton (1981) for an in-depth treatment of effective tax rates, and Auerbach (1982) for a discussion of the connection between effective tax rates and neutral business taxation.
} 
In words, the firm would be allowed to deduct $\left[\delta^{k}-\left(\pi^{k}-\pi\right)\right]$ percent of the asset's remaining value in each period. This deduction would cover the actual loss of value in nominal terms $\left[p^{k}\left(\delta^{k}-\pi^{k}\right)\right]$ plus the amount needed to maintain the asset's real value in the face of aggregate price inflation $\left(p^{k} \pi\right)$. The total deduction in equation 4 is exactly the sum of depreciation and (real) revaluation in the user cost of capital (see equation 3). If this depreciation policy were paired with a deduction for real interest expenses, the combination would grant a deduction for the full user cost of capital. Because the user cost represents the one-period charge that would prevail in a competitive rental market, allowing firms that own (rather than rent) capital to deduct the equivalent of the full user cost means that tax policy would be neutral with respect to the choice of renting versus purchasing capital. ${ }^{5}$

An example may help clarify how the allowances specified by equation 4 would work in practice. Assume, as in the previous example, that a new PC costs $\$ 1000$ and that its value declines 45 percent with each year of service. In addition, assume that the overall inflation rate is five percent annually. With these assumptions, $\delta^{k}-\pi^{k}$ is 45 percent and $\delta^{k}-\left(\pi^{k}-\pi\right)$ is 50 percent. As shown in the first line of table 2, the PC's initial value (column 1) falls to $\$ 550$ at the end of the first year (column 2). With an inflation rate of five percent, the firm would need $\$ 1050$ of PC capital at the end of the first year (column 3) to maintain the real value of its initial $\$ 1000$ stock in terms of other goods and services in the economy; the difference between $\$ 1050$ and $\$ 550$ gives rise to the $\$ 500$ tax deduction (column 4). This $\$ 500$ deduction equals

\footnotetext{
${ }^{5}$ This statement assumes that all firms face the same tax rate. If not, a firm with a low tax rate would still have an incentive to lease capital from a firm with a higher rate, as the higher-rate firm would realize greater value from the depreciation deductions.
} 
$\left[\delta^{k}-\left(\pi^{k}-\pi\right)\right]$ percent of the PC's initial value of $\$ 1000$. Lines 2 through 5 of the table repeat this calculation for subsequent years, with the PC assumed to be scrapped at the end of year five.

\section{Consumption of Fixed Capital and Capital Stocks in National Accounts}

The Bureau of Economic Analysis (BEA) publishes estimates of capital consumption for the U.S. economy in the NIPAs. In concept, the national accounts measure capital consumption as the outlay required to keep the capital stock intact. This notion, while quite intuitive, has generated a surprising amount of controversy in the literature on capital measurement. At the risk of oversimplifying the debate, the key issue is whether the change in asset value that we have labelled "revaluation" should be included in the consumption of fixed capital.

An important source of guidance on this issue is the 1993 System of National Accounts (SNA), a comprehensive set of macroeconomic accounts prepared jointly by the World Bank, the International Monetary Fund, the OECD, the Commission of the European Communities, and the United Nations. Unfortunately, the standards set out in the 1993 SNA are contradictory. On the one hand, the SNA states that:

"The value of a fixed asset ... is determined by the present value of the future rentals ... that can be expected over its remaining service life. Consumption of fixed capital is therefore measured by the decrease, between the beginning and the end of the current accounting period, in the present value of the remaining sequence of rentals." (Section 6.182)

This definition of capital consumption includes what we have called the revaluation effect, which is one of several factors that influence the value of an asset's future rental income. However, the SNA also constructs a revaluation account - separate from the measurement of capital consumption allowances - that records the gain or loss in value that "... "accrue[s] purely 
as a result of holding assets over time without transforming them in any way" (Section 12.67).

The revaluation effect for PCs is clearly a holding loss under this definition. Given these conflicting definitions, the SNA does not settle whether revaluation should be part of the consumption of fixed capital in national accounts.

Central to this controversy are different interpretations of what it means to "hold capital intact" for the purpose of measuring net income. One interpretation states that capital has been held intact if the physical quantity of capital has been maintained. By this definition, capital consumption would consist only of what we have called depreciation, which represents the outlay needed to cover the loss of value associated with wear-and-tear, declines in efficiency, and asset retirements. A contrasting point of view is that capital has been held intact if the ability of the capital stock to produce future income has been maintained. In this case, capital consumption would include not only depreciation but also the revaluation of existing assets. This second view underlies the tax allowance for depreciation described above. These competing interpretations of what it means to hold capital intact date back at least to the debate among Hayek (1941), Pigou (1941), and Hicks (1942), and economists have yet to settle this issue. $^{6}$ Going forward, it will be important for researchers and statistical agencies to reach a consensus regarding the appropriate measurement of capital consumption in national accounts.

This debate notwithstanding, the NIPAs currently exclude revaluation effects from the consumption of fixed capital, with these effects appearing in a separate revaluation account.

\footnotetext{
${ }^{6}$ For more recent views on this question, see Christensen and Jorgenson (1995), who construct an integrated set of national accounts using the narrower notion of capital consumption, and Hill $(1999,2000)$, who argues for the broader definition that includes revaluation.
} 
Accordingly, if we let $W_{t}^{k}$ denote the total value of all type- $k$ capital goods in year $t$, the NIPA capital consumption allowance for this asset is simply:

$$
C F C_{t}^{k}=W_{t}^{k} \delta^{k}
$$

Because this expression excludes revaluation effects, the NIPA concept of capital consumption measures the outlay needed to maintain the physical quantity of capital, not the future income stream from this capital.

The capital stock in equation 5 represents what is known in the literature as a "wealth" stock (which motivates our use of the symbol $W$ ). This wealth stock equals the sum of the current year's investment in capital goods of type $k$ plus the remaining value of the investment done in previous years. If we let $I_{t}^{k}$ denote this investment in year $t$ and assume that the asset has a service life of $T$ years, the wealth stock in current dollars can be expressed as:

$$
W_{t}^{k}=\sum_{i=0}^{T-1} I_{t-i}^{k}\left[1-\left(\delta^{k}-\pi^{k}\right)\right]^{i}
$$

In our previous example involving personal computers, we assumed that $\delta^{k}-\pi^{k}$ (the combined effect of depreciation and revaluation) is 45 percent annually and that PCs are scrapped after five years. With these assumptions, the wealth stock of PCs in year $t$ would be $\left(I_{t}^{k}+I_{t-1}^{k} 0.55+I_{t-2}^{k} 0.55^{2}+I_{t-3}^{k} 0.55^{3}+I_{t-4}^{k} 0.55^{4}\right)$ 
These expressions for the consumption of fixed capital and the wealth stock are in current dollars. That is, the wealth stock in equation 6 represents the actual dollar value of personal computers (or any other type of asset) in year $t$. Similarly, the measure of capital consumption in equation 5 represents the actual dollar outlay on personal computers required in year $t$ to maintain the stock of PCs intact (according to the NIPA concept). These series also can be expressed in terms of constant dollars. Of particular importance, a constant-dollar measure of capital consumption is needed to convert the economy's constant-dollar gross product into a figure for its constant-dollar net output. The capital consumption allowance for asset $k$ in constant dollars is simply the current-dollar measure divided by the price deflator for that asset. Dividing both sides of equation 5 by this price deflator yields the expression for capital consumption in constant dollars:

$$
C F C_{t}^{k, 1996 \$}=W_{t}^{k, 1996 \$} \delta^{k}
$$

where we assume that constant-dollar series are measured in 1996 dollars. $^{7}$

The constant-dollar wealth stock in equation 7 can be computed directly from constantdollar investment flows. ${ }^{8}$ As we demonstrate in the appendix,

\footnotetext{
${ }^{7}$ This was the NIPA convention when we completed the paper in November 2003. However, the comprehensive NIPA revision one month later shifted the base year for constant-dollar series from 1996 to 2000. This change in base year has no effect on the results in the paper, all of which could be re-expressed in year-2000 dollars. Note also that equation 7 shows the constant-dollar $\mathrm{CFC}$ for a single type of capital good. BEA calculates an aggregate real $\mathrm{CFC}$ by Fisher chain-weighting the constant-dollar CFCs for individual assets. In this paper, we focus on measuring the CFC (and wealth stock) for a single asset type - personal computers - and abstract from the calculation of chainweighted aggregates.

${ }^{8}$ One can also arrive at the constant-dollar wealth stock by deflating the current-dollar stock shown in equation 6 . We focus on the direct calculation of the constant-dollar stock from constant-dollar investment spending because that is the procedure used by BEA.
} 


$$
W_{t}^{k, 1996 \$}=\sum_{t=0}^{T-1} I_{t-i}^{k, 1996 \$}\left(1-\delta^{k}\right)^{i}
$$

Note that the investment weights here are $\left(1-\delta^{k}\right)^{i}$, rather than $\left[1-\left(\delta^{k}-\pi^{k}\right)\right]^{i}$ as in the expression for the current-dollar stock. The weights in equation 8 represent the value in year $t$ of one constant-dollar of past investment. As the algebra in the appendix shows, the price deflator used to construct constant-dollar investment in equation 8 embeds the revaluation effect $\left(\pi^{k}\right)$ for existing assets. Hence, one constant dollar of investment from (say) year $t-2$ would be worth less than a constant dollar from year $t$ solely because of aging effects $\left(\delta^{k}\right)$; including $\pi^{k}$ in the weight would double-count the revaluation effect. This explains why the investment weights for the constant-dollar stock in equation 8 differ from those for the current-dollar stock in equation $6 .{ }^{9}$

\section{Summary and Implications for Our Empirical Framework}

This section has covered a lot of ground. To review the key results, table 3 summarizes the implications of our discussion for calculating the user cost of capital, for specifying tax allowances for depreciation, and for measuring capital consumption allowances and wealth stocks in the NIPAs. As shown in table 3, the combined effect of depreciation and real revaluation, $\delta^{k}-\left(\pi^{k}-\pi\right)$, plays a central role in the analysis. It represents the percentage loss of

\footnotetext{
${ }^{9}$ A related point concerns the distinction between wealth stocks, which measure the value of existing assets, and socalled "productive" stocks, which measure the services provided by these assets in a given period. Productive stocks are the appropriate concept of capital to use when estimating production functions or when measuring the contribution of capital accumulation to the growth of output or productivity. The constant-dollar productive stock for a given asset, like the constant-dollar wealth stock, is calculated as a weighted sum of current and previous constant-dollar investment flows. However, the weights generally differ, as the weights for the wealth stock reflect the remaining value of each investment cohort, while those for the productive stock reflect its remaining efficiency. This paper deals with the measurement of wealth stocks, although the information we develop on retirement patterns for PCs is also relevant for measuring productive stocks.
} 
value, in real terms, experienced by an asset over the course of a year. This loss of value appears in the user cost of capital, and it constitutes the appropriate percentage deduction for tax purposes.

We also need to measure $\left(\delta^{k}-\pi^{k}\right)$ and $\delta^{k}$ to calculate certain items in table 3. $\delta^{k}-\pi^{k}$ represents the rate of decline in the asset's nominal value, which enters directly into the calculation of the current-dollar wealth stock and also determines the asset price $\left(p^{k}\right)$ that appears elsewhere in table 3. $\delta^{k}$ measures the pure effect of aging on asset value and is needed to compute the constant-dollar wealth stock from data on constant-dollar investment outlays and to calculate the consumption of fixed capital in the NIPAs.

Our empirical strategy will be to estimate $\delta^{k}$ and $\delta^{k}-\left(\pi^{k}-\pi\right)$ directly from data on used PC prices and then to calculate $\delta^{k}-\pi^{k}$ by subtracting the rate of aggregate price inflation, $\pi$, from the estimate of $\delta^{k}-\left(\pi^{k}-\pi\right)$. To see how we estimate these parameters, consider a simple $\log$-linear expression for the price of a PC in year $t$ scaled by the aggregate price index in that year:

$$
\ln \left(p_{z, t, a}^{k} / p_{t}\right)=\alpha+\beta \ln z+\gamma t+\phi a
$$

For purposes of illustration, we have written this equation with only a single performance characteristic $(z)$, and we have assumed that the effects of age and time on price are constant. (We do not impose these constraints in our actual estimation.) Because this regression equation controls for the PC's quality, the coefficient on time, $\gamma$, measures the rate at which constantquality PC prices fall relative to the aggregate price level. This is exactly $\left(\pi^{k}-\pi\right)$ in our 
notation. Similarly, the coefficient on age, $\phi$, measures the pure effect of aging on PC prices, which is minus $\delta^{k}$ in our notation (the minus sign appears because we have expressed the rate of depreciation, $\delta^{k}$, as a positive number). Thus, - $\phi$ provides the estimate of $\delta^{k}$, and $-(\phi+\gamma)$ provides the estimate of $\delta^{k}-\left(\pi^{k}-\pi\right)$.

\section{DATA}

The data used in this paper were obtained from Orion Research, which publishes bluebooks for many different used goods, including computers. The computer bluebooks contain prices for various types of used computer equipment and peripherals, based on surveys of used equipment dealers. The bluebook entry for each PC includes information on the manufacturer, the model name and number, and the year or years in which the model was sold new by the manufacturer. Each bluebook entry also includes detailed information about the characteristics of the PC, including the processor type (Pentium III, for example), the processor speed, the amount of random access memory, and the size of the hard disk. ${ }^{10}$

Orion's survey form asks dealers to show the amount paid to the seller of the PC (i.e., the wholesale price) as well as the dealer's retail selling price and the number of days it took the dealer to sell the PC. Using this information, Orion constructs three used prices for each bluebook entry: the wholesale prices for units in "mint" and "average" condition, and the "current used" price, which measures the average retail price for units sold in 30 days or less.

\footnotetext{
${ }^{10}$ In many cases, several additional characteristics were also listed, including whether the PC has a DVD player, a fax/modem, a video card, a sound card, or a network card. However, the reporting of these features appears to be less consistent across models and across years.
} 
We focus on the "current used" price for our empirical work, but our results would be virtually the same if we used either wholesale price instead.

We collected data on prices and characteristics of desktop PCs from the Orion bluebooks published from 1985 through 2003. Four major computer makers were included in the sample: Compaq, IBM, Dell, and Packard Bell. From 1995 to 2003, we use the Winter edition of the bluebook, published in January of each year. According to Orion, the prices in the Winter edition are based on survey data collected in the fourth quarter of the previous year. In 1993 and 1994, only the Fall edition was available; these prices reflect data collected in the third quarter of each year. Prior to 1993, the bluebooks were published annually, usually at about mid-year, so we assume that the prices in these books were observed in the first half of the year.

The concept of age in our dataset warrants some discussion. The bluebook description of a PC for sale never includes its age. This omission reflects the fact that the value of a PC depends on its characteristics and its general condition; given this information, the date that the manufacturer shipped it from the factory is unimportant. However, a second concept of age which we use in our empirical work - is relevant for pricing. We define "model age" as the amount of time that has elapsed since the first shipment of a given model. For example, the Dell "Dimension 8100" with a Pentium IV processor was first sold in 2001, while an earlier model, the "Dimension V350" with a Pentium II processor, was first sold in 1998. When measured in terms of model age, the V350 units are three years older than the 8100 units. The older model would be expected to sell at a lower price both because it is a less powerful computer and because it likely has fewer remaining years of use before obsolescence causes retirement to occur. 
Because PCs depreciate quickly, it is important to be as precise as possible about the timing of the observed prices. Table 4 lists each edition of the bluebooks included in our sample along with the time period in which, to the best of our knowledge, the prices were observed. We construct the time and age variables for our empirical work at the monthly frequency using the midpoint of the date range for the survey period. For example, we assign the price observations from the 2001 bluebook to November of the prior year. To calculate model age, we assume that a given model was first shipped in June of the year it was introduced. Model age is then defined as the number of months between the (assumed) first-shipment date and the survey date. For instance, the 2001 bluebook price for a PC listed as first sold in 1998 would be associated with a model age of 29 months (June 1998 to November 2000). Figure 1 illustrates the resulting distribution of observations by model age. As can be seen, our dataset contains a large number of observations in each age group.

In previous work, Dulberger (1989) and Oliner (1993) found that, even after controlling for performance characteristics, the prices of semiconductors and mainframe computers varied significantly depending on whether they were near the frontier of the technologies available at the time a price was observed. This finding was taken as evidence of disequilibrium in these markets. We allow for the possibility of a similar pattern in the market for PCs. Accordingly, we construct a dummy variable (denoted FAST) that distinguishes models with best-practice technology from all other models. FAST equals one if the PC's processor speed is in the highest 10th percentile of chip speeds available at the time of the price observation.

For the regressions that follow, we exclude observations that are missing data on price or the major performance characteristics. In addition, we exclude used PCs with prices greater than 
$\$ 10,000$, because they are likely to be servers rather than personal computers, the desired focus of our study. The final sample contains 12,896 observations. Table 5 lists the mean values of various characteristics by the year in which the used PC was sold. As can be seen in the table, large advances in chip speeds and memory have been accompanied by rapid declines in the price of used PCs.

\section{ESTIMATION AND RESULTS}

This section presents the results of the hedonic regression that we use to estimate various aspects of price change for personal computers. The dependent variable is the log of the used PC price deflated by the GDP chain-weight price index, while the explanatory variables include product characteristics and functions of time and the PC's model age. We allow the effects of time to vary in the usual way by including separate dummy variables for all but one of the 19 periods in which prices were observed. However, the dummy variable approach works less well for model age because of the large number of different ages in our sample. To simplify the regression but still allow for a wide range of age-related price movements, we employ a fourthorder polynomial function of model age. Thus, the general form of our regression equation is:

$$
\ln \left(p_{z, t, a}^{k} / p_{t}\right)=\alpha+\sum_{i} \beta_{i} \ln z_{i}+\sum_{n=1}^{18} \gamma_{n} t_{n}+\sum_{j=1}^{4} \phi_{j} a^{j}
$$

The vector $\mathbf{z}$ of product characteristics includes the log of the CPU speed (denoted by $M H Z$ ), the $\log$ of the amount of random access memory (RAM), the log of hard disk size (HD), a dummy 
variable for whether the price for the PC includes a monitor $(M O N)$, a dummy for whether the PC has a CD-ROM or DVD (CDROM), and the FAST chip dummy variable. We also include brand dummies for Compaq, IBM, and Packard Bell (with Dell as the excluded dummy) to control for differences among the four brands in the sample. With these controls for quality, the equation becomes:

$$
\begin{aligned}
\ln \left(p_{z, t, a}^{k} / p_{t}\right) & =\alpha+\beta_{1} \ln M H Z+\beta_{2} \ln R A M+\beta_{3} \ln H D+\beta_{4} \ln M O N \\
& +\beta_{5} \ln C D R O M+\beta_{6} F A S T+\beta_{7} C O M P A Q+\beta_{8} I B M+\beta_{9} P B E L L \\
& +\sum_{n=1}^{18} \gamma_{n} t_{n}+\sum_{j=1}^{4} \phi_{j} a^{j}
\end{aligned}
$$

\section{Regression Results}

The column labeled "Baseline" in table 6 presents the results from OLS estimation of equation 11. As shown in the table, the regression fits the data quite well, with an adjusted Rsquared of 0.92. Moreover, the coefficients on all of the performance characteristics except the FAST dummy variable are strongly significant and have the expected positive signs. Among these characteristics, differences in processor speed have the largest price effects, consistent with previous findings by Oliner (1993), Dulberger (1989), and Cartwright (1986). The brand effects are also significant, revealing a large price discount for Packard Bell PCs relative to other brands with similar product characteristics.

The coefficients on model age are all significant, with those on the higher-order terms especially so. As a result, we can strongly reject the hypothesis that the coefficients on $a^{2}, a^{3}$, 
and $a^{4}$ are jointly zero, which means that the used PC prices do not decline at a constant rate with model age. That is, the estimated age-price profile is not geometric. ${ }^{11}$

In addition, the coefficients on the time dummies fall sharply over the sample period. As noted earlier, these coefficients represent the rate of decline in constant-quality PC prices relative to GDP prices. The coefficients on the time dummies for March 1985 and November 2002 imply that constant-quality PC prices dropped at an average annual rate of 35.1 percent in real terms between these dates. ${ }^{12}$ After accounting for the rise in GDP prices over this period, this figure implies that constant-quality PC prices fell in nominal terms at an average annual rate of 32.7

\footnotetext{
${ }^{11}$ Age-price profiles estimated from used asset prices - as in this paper - can be affected by the "lemons" problem first identified by Akerlof (1970). Akerlof showed that prices on second-hand markets may embed a lemons discount when buyers cannot assess the quality of the goods offered for sale and thus presume that sellers are attempting to pass off inferior goods. In this case, the observed prices for units of a given age will provide a downward biased estimate of the average price for all units of that age. Although we cannot rule out a lemons bias in our data, we doubt this is a serious problem. Importantly, the condition of a used PC can be assessed rather easily, which limits the information asymmetry that lies behind the lemons issue. Even someone with minimal knowledge of computers could detect whether a PC has significant defects by visually inspecting the unit and checking that its key components operate properly. In addition, we performed a simple empirical test that failed to turn up evidence of a lemons problem. In particular, we re-ran the baseline regression using the wholesale prices for units in mint condition instead of the retail prices. These wholesale prices measure what the dealers - who tend to be sophisticated buyers - paid for the PCs that they assessed to be in excellent condition. If our baseline regression were affected by a lemons problem, we might expect the age-price profile based on wholesale mint prices to differ from that based on retail prices. However, the two profiles were virtually the same.

${ }^{12} \mathrm{We}$ measure this average annual rate of real price decline as $100 \times\left[\left(\frac{p_{z, t=11 / 02, a}^{k} / p_{t=11 / 02}^{G D P}}{p_{z, t=03 / 85, a}^{k} / p_{t=03 / 85}^{G D P}}\right)^{1 / 17.67}-1\right]$, where
}

17.67 years elapse between the two pricing dates and we use the values of the GDP chain-weight price index for the quarters containing these pricing dates. We then calculate the price ratio in parentheses as follows, where the second equality is based on equation 11:

$$
\frac{p_{z, t=11 / 02, a}^{k} / p_{t=11 / 02}^{G D P}}{p_{z, t=03 / 85, a}^{k} / p_{t=03 / 85}^{G D P}} \equiv \exp \left[\ln \left(p_{z, t=11 / 02, a}^{k} / p_{t=11 / 02}^{G D P}\right)-\ln \left(p_{z, t=03 / 85, a}^{k} / p_{t=03 / 85}^{G D P}\right)\right]=\exp \left[\gamma_{11 / 02}-\gamma_{03 / 85}\right],
$$

with $\gamma_{11 / 02}$ and $\gamma_{03 / 85}$ denoting the coefficients on the time dummies for those dates. All other coefficients in equation 11 drop out from the calculation. 
percent. This pace is similar to estimates of quality-adjusted price change for PCs in Berndt and Rappaport (2003) and in Geske, Ramey, and Shapiro (2003). ${ }^{13}$

The rate of price decline that we estimate is more rapid than the drop in BEA's constantquality price index for personal computers, which fell at an average annual rate of 21.5 percent over 1985-2002. Diagnosing the source of this gap would require an analysis beyond the scope of this paper. There are a host of possible reasons for the gap - including differences in source data, hedonic techniques, and the construction of price indexes - that should be explored in future research.

For the time being, however, we focus on the implications of this difference for the measurement of depreciation. Recall that the total change in a capital good's price over a given time period is the sum of depreciation and constant-quality price change (the revaluation effect). In the various specifications that we tested, we found that the estimate of the overall price change was tightly nailed down, while the individual components were less so; as a result, speeding up the decline in constant-quality prices had the effect of reducing the depreciation rate by roughly the same amount. Given this negative correlation between the components, the depreciation rate we estimated conditional on the constant-quality price change in our dataset would not be appropriate for use in conjunction with the NIPA measure of constant-quality prices for PCs, which falls more slowly than our measure. To produce a depreciation estimate that would be suitable for use in the NIPAs, we re-estimate the baseline regression after constraining the path

\footnotetext{
${ }^{13}$ However, Pakes (2003) found a notably slower pace of quality-adjusted price decline for PCs - roughly 15 to 20 percent per year on average. See Landefeld and Grimm (2000) for a comparison of results from earlier studies and Berndt and Rappaport (2001) for additional background on the estimation of hedonic indexes for PCs.
} 
for constant-quality prices in our data to conform with the BEA series. We impose this constraint

by replacing the time dummies in equation 11 with the natural $\log$ of $\left(p_{t}^{P C, B E A} / p_{t}^{G D P}\right)$, which is forced to have a coefficient equal to one.

The results of this regression are shown in the column labelled "Imposed PC price." As can be seen from the drop in the adjusted R-squared from 0.92 to 0.84 , the overall fit of this regression is not as good as the baseline regression, reflecting the imposition of a trend rate of constant-quality price change that conflicts with the pattern in the data. This constraint affects the estimates of some other coefficients in the regression. In particular, the coefficient on $\ln (M H Z)$, which was strongly positive in the baseline regression, turns slightly negative in the constrained regression. Moreover, the $F A S T$ chip dummy becomes positive and highly significant. The coefficients on model age also change quite a bit, and we examine the effects of these changes on the estimated age-price profile for PCs in the next subsection.

\section{Price Profiles}

Tables $7 \mathrm{a}$ and $7 \mathrm{~b}$ present the estimated price profiles for PCs that we need to explore the implications of our results for tax policy and for capital measurement in the national accounts. Table $7 \mathrm{a}$ uses the coefficient estimates from the baseline regression, while table $7 \mathrm{~b}$ employs those from the constrained regression. Both tables have the same structure, allowing an easy comparison of results. All of the price profiles in both tables have been normalized to equal 100 for new models. 
Beginning with table 7a, column 1 shows the age-price profile implied by the coefficients on model age in the baseline regression. ${ }^{14}$ These coefficients capture the age-related decline in price across models at a given time, controlling for differences in performance characteristics. As can be seen, the age-price profile in column 1 is essentially flat for the first 12 months of model age before declining steadily to about 56 percent of initial value at the 78-month mark.

This age-price profile is based on prices for PCs that are still in use and does not account for the units that already have been removed from service. Because these retired PCs presumably had a low implicit price relative to those that remained in use, the age-price profile in column 1 provides an upward biased estimate of the expected profile for an initial cohort of PCs. To correct this bias, we follow the procedure in Hulten and Wykoff (1981a, 1981b) and Oliner (1993). On the assumption that the salvage value of retired PCs is zero, we multiply the age-price profile in column 1 by the survival probabilities from an assumed retirement distribution. In particular, let $g(a)$ be the age-price profile from our regression, and let $S(a)$ be the survival function representing the probability that a PC will remain in service at age $a$. Then, the ageprice profile corrected for retirements is $S(a) g(a){ }^{15}$

\footnotetext{
${ }^{14}$ Each entry in column 1 equals $100 \times\left(p_{z, t, a=a^{*}}^{k} / p_{z, t, a=0}^{k}\right)$, where $a^{*}$ varies from zero months to 78 months in
} six-month increments. We calculate this price ratio as follows, where the second equality is based on equation 11 :

$$
\begin{aligned}
p_{z, t, a=a^{*}}^{k} / p_{z, t, a=0}^{k} \equiv & \exp \left[\ln \left(p_{z, t, a=a^{*}}^{k} / p_{t}^{G D P}\right)-\ln \left(p_{z, t, a=0}^{k} / p_{t}^{G D P}\right)\right] \\
& =\exp \left[\phi_{1} a^{*}+\phi_{2}\left(a^{*}\right)^{2}+\phi_{3}\left(a^{*}\right)^{3}+\phi_{4}\left(a^{*}\right)^{4}-\left(\phi_{1} \times 0+\phi_{2} \times 0^{2}+\phi_{3} \times 0^{3}+\phi_{4} \times 0^{4}\right)\right] \\
& =\exp \left[\phi_{1} a^{*}+\phi_{2}\left(a^{*}\right)^{2}+\phi_{3}\left(a^{*}\right)^{3}+\phi_{4}\left(a^{*}\right)^{4}\right]
\end{aligned}
$$

${ }^{15} \mathrm{An}$ alternative way to adjust for retirements would be to multiply each price observation in our sample by the survival probability associated with that observation and then to run the regression with the adjusted data. We tried both methods and found that the results were virtually the same either way. 
Unfortunately, very little is known about retirement patterns for PCs. The limited evidence suggests that the modal age at retirement is roughly four years. ${ }^{16}$ Because many PCs probably continue to be used in lower-value applications for a number of years, we assumed that the mean age of retirement is five years, one year longer than the modal age. We then selected an asymmetric retirement distribution that matched these parameter values. Although the Winfrey distributions have a long history in economics for portraying retirement patterns, we used the Weibull distribution instead because of its convenient parametric form. ${ }^{17}$

The survival probabilities generated by our retirement distribution are shown in column 2 . As can be seen, this distribution implies that 88 percent of PCs remain in service after 24 months of use, after which the pace of retirements picks up. The probability of retirement is highest over the range from 36 to 60 months of use, and then slows, leaving a long right-hand tail to the distribution. Column 3 shows our estimated age-price profile adjusted for retirements, calculated as the product of columns 1 and 2 . This column represents our estimate of depreciation $\left(\delta^{k}\right)$, taking account of the implicit zero price on retired units.

The next column presents the real revaluation effect $\left(\pi^{k}-\pi\right)$, which equals the estimated rate of decline in constant-quality PC prices relative to the path for GDP prices. As noted above, this real decline in PC prices averaged 35.1 percent annually over our full sample period. Column 4 shows the cumulative effect of this real revaluation for successively older models.

\footnotetext{
${ }^{16}$ A recent story on the Bloomberg News Service (2003) cited an industry analyst who suggested that, in the recent past, large firms have been replacing PCs every four years. In addition, Richards (2002) estimated that the replacement cycle for PCs is 3.9 years, based on spectral analysis of computer investment flows.

${ }^{17}$ Outside of economics, the Weibull distribution has been used extensively to model survival patterns. See Johnson, Kotz, and Balakrishnan (1994). Among applications in economics, Sliker (2003) has used the Weibull to model retirement patterns for motor vehicles. The survival function implied by our Weibull retirement distribution is $\exp \left[-(\mathrm{age} / \beta)^{\eta}\right]$ where $\beta=67.8, \eta=2$, and age is measured in months.
} 
Columns 5 through 7 bring together the separate influences on PC prices. Column 5 presents the combined effect of depreciation and real revaluation, calculated as the product of the profiles in columns 3 and 4 . The rate of decline shown in column 5 is the estimate of $\delta^{k}-\left(\pi^{k}-\pi\right)$, which figures so prominently in our measurement system. If aggregate price inflation were zero, $\delta^{k}-\left(\pi^{k}-\pi\right)$ would equal $\delta^{k}-\pi^{k}$, and this column would represent the actual drop in the value of a personal computer with each additional period of use - hence the label "No Inflation" for this column. As can be seen, the value of a PC declines quickly after it enters service. Twelve months after installation, the PC's value has fallen to 62.5 percent of its initial price, almost entirely reflecting revaluation; after 24 months, only 33.5 percent of the initial value remains, and after 60 months the PC is nearly worthless. Columns 6 and 7 show the analogous schedules when aggregate price inflation is 1 percent and 4 percent, respectively - the range observed over our sample period. As is evident from the similarity of the three columns, the strong downward pressure on PC prices from revaluation and age-related factors overwhelms the effect of aggregate price inflation.

The price profiles in table $7 \mathrm{a}$ are the ones implied by our unconstrained baseline regression. We will use these profiles in section 5 to assess the implications of our results for tax depreciation schedules for PCs. However, as we discussed above, the baseline regression implies that constant-quality PC prices have declined considerably faster than is indicated by the BEA series. To obtain price profiles that mesh with BEA's constant-quality price index, table $7 \mathrm{~b}$ recalculates all the profiles using the results from the constrained regression.

The age-price profile in column 1 of table $7 \mathrm{~b}$ declines more rapidly than its counterpart in table 7a. This difference is a direct result of imposing the BEA price index in the constrained 
regression. That is, the slower rate of constant-quality price decline in the constrained regression forces adjustments in other coefficients to fit the sharp drop in bluebook prices for a given PC over its service life. One such adjustment, shown in column 1, is a speed-up in the estimated rate of age-related price decline, which carries through to the survival-adjusted age-price profile in column 3 (after applying the unchanged survival function). This age-price profile differs substantially across the two tables. Indeed, over the first 60 months of the PC's service life, the average annual rate of depreciation is 34.6 percent in table $7 \mathrm{~b}$, well above the 22.4 percent rate in table $7 \mathrm{a}$.

This difference offsets virtually all of the gap in the estimated revaluation rate between the constrained and unconstrained regressions, as can be seen by comparing column 5 across the two tables. After 36 months of use, the PC's remaining value (taking account of both depreciation and revaluation) is 16.2 percent in table 7 a, very similar to the 17.2 percent figure in table $7 \mathrm{~b}$. The difference becomes even smaller with additional periods of use. Thus, the data enforce a strong negative correlation between the estimated rates of depreciation and constant-quality price change, leaving their sum largely invariant to constraints imposed on either component.

\section{Alternative Regressions}

Table 8 summarizes the main results from our empirical work. It also presents several tests of robustness and briefly compares our results to those in Geske, Ramey, and Shapiro (2003), abbreviated henceforth as GRS. Column 2 of the table shows the combined effect of depreciation and revaluation for various specifications of our regression, while columns 3 and 4 display these two components of price change. Column 5 shows the cross-product term that 
arises when combining the effects of depreciation and revaluation. ${ }^{18}$ We present these price measures from:

- the baseline regression (line 1);

- the constrained regression that imposes BEA's PC price index (line 2);

- alternative versions of the baseline regression that enlarge the set of performance characteristics (line 3), that allow the coefficients on the characteristics to vary over time (line 4), and that use wholesale PC prices rather than retail prices as the dependent variable (line 5);

- the baseline regression estimated over the 1990-2000 sample period used by GRS (line 6); - $\quad$ and two sets of results from GRS (lines 7 and 8).

Perhaps the key point to take away from the table is shown in column 2: namely, the various regression specifications all imply that the value of a PC falls roughly 50 percent on average over the course of a year. The estimates of this annual price decline are tightly clustered in a range from about 47 percent to 52 percent, despite substantial differences in the form of the regression, the presence or absence of constraints, and the estimation period. Thus, as noted above, the data yield a robust estimate of the combined effect of depreciation and revaluation on PC prices.

However, the decomposition of this total price change between depreciation and revaluation is less certain. The baseline specification using the full sample (line 1) implies an

\footnotetext{
${ }^{18}$ Specifically, column 2 displays the value of $\omega^{k}$ from the equation $\left(1-\omega^{k}\right)=\left(1-\delta^{k}\right)\left(1+\pi^{k}\right)$, with $\delta^{k}$ shown in column 3, negative $\pi^{k}$ in column 4 , and $\delta^{k} \pi^{k}$ in column 5. $\omega^{k}$ equals $\left(\delta^{k}-\pi^{k}\right)+\delta^{k} \pi^{k}$ (i.e., the sum of columns 3,4 , and 5). We measure $\delta^{k}$ as the average annual decline in the survival-adjusted age-price profile over the initial 60 months of the PC's service life. Also, we measure $-\pi^{k}$ as the average annual rate of constant-quality price decline for PCs over the time period shown in column 1.
} 
annual (survival-adjusted) depreciation rate of 22.4 percent and a (nominal) revaluation rate of 32.7 percent. Imposing the BEA constant-quality price index for PCs essentially reverses the relative magnitudes of depreciation and revaluation. This shift highlights that the estimate of depreciation depends on the assumed rate of constant-quality price change. Line 3 shows that the estimates of depreciation and revaluation also depend somewhat on the control variables included in the regression. To obtain the result reported on line 3, we augmented the baseline set of performance characteristics with a set of dummy variables for the type of central processor chip in the PC. These dummies indicate whether the processor is a 286, 386, 486, Pentium I, Pentium II, Pentium III, or Pentium IV. The CPU dummies could be viewed as capturing some unmeasured dimensions of quality to the extent that processor speed and memory - the standard measures - do not fully determine the processor's capabilities. We find that these CPU dummies are significant in the regression and, as shown on line 3, their presence tends to slow the rate of depreciation while increasing the rate of revaluation. ${ }^{19}$

We also examined whether the coefficients on the characteristics change over time and whether any such variation affects the estimates of depreciation and revaluation. This issue is particularly important in light of Pakes' (2003) critique of standard hedonic procedures. Pakes argued that the coefficients in hedonic regressions may change over time in response to changes in market structure or preferences. For similar reasons, he also argued that caution is required in interpreting these coefficients and that they need not have the "expected" signs. To examine

\footnotetext{
${ }^{19}$ The interpretation of these CPU dummies is subject to some ambiguity. As noted in the text, they could be significant because they proxy for unmeasured elements of quality. However, the CPU dummies are also correlated with a PC's model age. Indeed, GRS use a similar variable to account for the depreciation that they estimate in a regression similar to our baseline specification. If the CPU dummies mainly function as proxies for model age rather than as proxies for unmeasured quality, the baseline specification would provide a more accurate measure of agerelated depreciation.
} 
these issues, we allowed the coefficient on each characteristic to differ across three sub-periods:

1985-95, 1996-99, and 2000-02. The coefficients on characteristics in this regression did vary somewhat over time, but as can be seen on line 4 of the table, the implied depreciation rate is the same as in the baseline regression and the revaluation rate is only a bit faster.

Lines 5 and 6 show the results of two other tests of the baseline regression. To explore robustness with respect to our price measures, we estimated the baseline regression using the wholesale price for PCs in average condition rather than the retail price. As can be seen on line 5, this change had very little effect on the estimated rates of depreciation and revaluation. ${ }^{20}$ Line 6 shows that using the GRS sample period (1990-2000) reduced the estimated depreciation rate only slightly relative to the baseline regression, while increasing the revaluation rate more substantially.

The final lines of table 8 present the results from GRS that most closely resemble our baseline and constrained regressions. The regression associated with line 7 allows the data to determine the rate of constant-quality price change, as in our baseline specification, while the regression associated with line 8 imposes BEA's price index for computers and peripheral equipment. $^{21}$ As we noted above, the total price decline shown on lines 7 and 8 closely

\footnotetext{
${ }^{20}$ The gap between wholesale and retail prices represents the dealer's margin, and in a competitive market, it measures the transaction cost of selling used PCs. One could be concerned that swings in dealer margins might influence our estimated price profiles. However, our nearly identical results using either wholesale or retail prices indicate that margins have not varied systematically over time or with the age of the PC.

${ }^{21}$ Lines 7 and 8 of the table reflect the results shown in GRS, table 6, columns 8 and 3, respectively. Several points should be noted about the GRS regression results. First, the BEA price series imposed on their regression covers all computers and peripheral equipment, not just PCs. This broader price index has tended to fall somewhat less rapidly than the index for PCs alone, which accounts for the relatively small revaluation effect on line 8 of our table. Second, GRS's results make no adjustment for retirements. We adjusted their age-price profiles with the survival function shown in our tables $7 \mathrm{a}$ and $7 \mathrm{~b}$, which places their depreciation estimates on the same conceptual footing as ours. Third, GRS allow for what they call "instantaneous depreciation," defined as the loss of value that occurs when a buyer opens the box containing a new PC. They attempt to identify this effect from the "new list" prices shown in the Orion bluebooks. Their estimates imply a large instantaneous loss of value, ranging from about 20 to
}

(continued...) 
approximates the pace that we estimate. However, the GRS depreciation rates are somewhat faster than ours, highlighting that there is a sizable confidence band around the estimates from our study and theirs concerning this element of price change.

\section{IMPLICATIONS}

This section explores the implications of our empirical results for tax policy, for capital accounting in the NIPAs, and for measuring the user cost of capital.

\section{Tax Depreciation Allowances for Personal Computers}

Under current tax rules (the "Modified Accelerated Cost Recovery System"), PCs and other types of computing equipment are depreciated over a five-year period. The annual deductions are calculated using the "double-declining-balance" (DDB) method with a switch to the straight-line method at the point that maximizes the present value of the deductions. The double-declining-balance method specifies an annual percentage deduction that is twice the straight-line rate. For an asset with a five-year recovery period, the DDB deduction rate would be 40 percent annually.

The first column of table 9 shows the stream of tax allowances for a PC under current law, with each year's deduction expressed as a percent of the asset's initial value. Note that the firstyear deduction - 20 percent - is only half of the full-year amount, reflecting a "half-year" convention that assumes the asset was put in place at mid-year. After this deduction, 80 percent

\footnotetext{
${ }^{21}(\ldots$... continued $)$

25 percent of the new PC price in the regression specifications that most resemble ours. However, this apparent loss of value could arise, at least in part, from unmeasured price discounts. That is, if new PCs actually sell at a discount to list price, the regression would overstate the price drop when a new PC leaves the store. Given this identification issue, we chose to exclude the new list prices from our dataset, and we present the GRS depreciation rates excluding their estimate of the instantaneous price decline.
} 
of the PC's initial value remains to be depreciated. Applying the 40 percent rate to this remaining value yields the 32 percent deduction for the second year. The third-year deduction is calculated in the same way. The schedule then switches to the straight-line pattern, with the undepreciated part of the PC's initial value written off over the remaining 2-1/2 year recovery period.

Given our assumed retirement distribution for personal computers, a substantial fraction of PCs would be retired before being fully depreciated under current tax rules. In such cases, the tax code allows a firm to deduct the full amount of the remaining allowances in the year of retirement. $^{22}$ The second column of the table adjusts the statutory allowance in column 1 to account for these early retirements. To make this adjustment, we use our estimated retirement distribution to divide a cohort of newly installed PCs into those that are retired in the first six months of service (to reflect the half-year convention), the next full year, the year after that, and so on. We then calculate the appropriate depreciation schedule for each sub-cohort. For example, the small fraction of PCs retired within the first six months of service would receive a 100 percent deduction in the first tax year; those retired between six months and eighteen months would receive the usual 20 percent deduction in the first tax year and the remaining 80 percent deduction in the second tax year. We proceed in this fashion for successive annual slices of the retirement distribution, and then aggregate the depreciation schedules for each slice using weights that equal the probability of retirement within that slice.

As can be seen by comparing columns 1 and 2, this adjustment results in a small acceleration of the statutory schedule of deductions. During the first two tax years, the adjusted

\footnotetext{
${ }^{22}$ See CCH(2002, p. 337), “Abandonment and Obsolescence Losses." The deduction would be reduced by the amount of any sale proceeds or insurance recovery. Implicitly, we have assumed that the asset is uninsured and has a salvage value of zero.
} 
allowances total 55.2 percent of the initial value of the PC cohort, up from 52 percent in the statutory schedule. This adjustment - while conceptually necessary - is fairly small because the early retirements in our distribution are concentrated in years four and five, after the bulk of the tax allowances have been taken.

We now compare the retirement-adjusted schedule in column 2 to the allowances implied by our empirical results. As discussed above, the allowance in a given period equals the PC's loss of value in real terms, which we calculate as the product of the PC's value at the beginning of a period and the real percentage decline in value that it experiences over the period. Both terms in this product were shown in tables $7 \mathrm{a}$ and $7 \mathrm{~b}$; we use the figures in table $7 \mathrm{a}$, which reflect the baseline (unconstrained) regression. Columns 5 through 7 in that table display the first term in the product - the PC's remaining value as it ages - under different rates of general price inflation. For the purpose of this exercise, we measure the PC's value at ages 6 months, 18 months, 30 months, and so forth to be consistent with the half-year convention in the tax code. The second term in the product, the real percentage decline in a PC's value during a given period $\left[\delta^{k}-\left(\pi^{k}-\pi\right)\right]$, is calculated from column 5 of table 7 a. Moving down that column gives the period-by-period values for $\delta^{k}-\left(\pi^{k}-\pi\right)$. For example, the real decline in value over the initial 6 months of use is 19.1 percent [ $1-(80.9 / 100)]$. To conform with the half-year convention, we use the rate of decline between 0 and 6 months, 6 and 18 months, 18 and 30 months, and the successive 12-month intervals.

Columns 3 through 5 of table 9 show the resulting schedule for depreciation allowances under different rates of aggregate inflation. Focus first on column 3, the schedule of allowances when the aggregate inflation rate is zero. This schedule is remarkably similar to the deductions 
allowed under current law after adjusting for early retirements, column 2. The first-year

deductions under both schedules are close to 20 percent of the PC's initial value, and the secondyear deductions are both a shade less than 35 percent. When we allow for general price inflation (columns 4 and 5), the deductions become slightly larger than in column 3 because the nominal value of the $\mathrm{PC}$ - its tax basis for our calculations - declines less rapidly in the higher inflation environment.

The bottom part of the table compares the present value of the deductions under the various schedules. To calculate these present values, we discount the annual deductions with a nominal after-tax interest rate of $3-1 / 2$ percent in the case of no inflation, $4-1 / 2$ percent when inflation is 1 percent, and 7-1/2 percent when inflation is 4 percent. ${ }^{23}$ With no inflation, the present value of the current-law deductions (adjusted for retirements) is $\$ 93.0$ per $\$ 100$ of initial asset value, virtually identical to the $\$ 92.9$ figure for deductions that cover the PC's full loss of value. However, the gap widens considerably when we introduce inflation. At 4 percent inflation, the present value of current-law deductions (again adjusted for retirements) is $\$ 86.1$, a fair amount less than the $\$ 92.3$ figure in column (5), as the higher inflation erodes the present value of the unindexed deductions under current law. ${ }^{24}$ Thus, the current-law deductions do an excellent job of approximating the full loss of value for personal computers under zero or very low inflation,

\footnotetext{
${ }^{23}$ Over our sample period, the real (pre-tax) interest rate on BAA-rated corporate bonds averaged about $5-1 / 2$ percent (where we compute the real rate as the nominal rate minus the expected ten-year inflation rate from the Philadelphia Federal Reserve Bank's survey of professional forecasters). Under Fisher's Law (modified to account for taxation), each percentage point of inflation adds $1 /(1-\tau)$ percentage points to the real interest rate, where $\tau$ represents the corporate tax rate, which we take to be 35 percent. The resulting nominal after-tax interest rate is $[5-1 / 2+\pi /(1-\tau)] *(1-\tau)=0.65 * 5-1 / 2+\pi$, which equals approximately $3-1 / 2$ percent when $\pi=0,4-1 / 2$ percent when $\pi=1$, and $7-1 / 2$ percent when $\pi=4$.

${ }^{24}$ Note that the present value differs slightly across columns (3)-(5), even though the PC's remaining value is adjusted for inflation in each case. The difference arises because, for simplicity, we have ignored the cross-product in Fisher's law between the real interest rate and the inflation rate as well as the cross-product between the real decline in PC prices and the aggregate inflation rate in the inflation-adjusted tax basis for depreciation.
} 
but the lack of indexation causes the tax deductions to fall short of this benchmark when inflation moves higher.

\section{Capital Accounting}

NIPA Wealth Stocks for Personal Computers. As described in BEA (1999), real NIPA wealth stocks are calculated by summing past real investment flows with weights generally based on the geometric depreciation rates estimated by Hulten and Wykoff (1981b). However, Hulten and Wykoff did their work prior to the widespread introduction of personal computers. Thus, BEA must look beyond the Hulten-Wykoff results for estimates of depreciation for PCs. Prior to the December 2003 comprehensive revision of the NIPAs, BEA used a depreciation schedule for PCs based on Lane (1999). This schedule is nearly geometric and assumes that the value of a PC declines to ten percent of its original value after five years. Importantly, this schedule incorporates the full loss in a PC's value as it ages, and thus captures both depreciation and revaluation. As we discussed in section 2, BEA's calculation of the real wealth stock should rely on weights that exclude revaluation. ${ }^{25}$

Based on a preliminary version of this paper, BEA decided to adopt a geometric depreciation rate of 34 percent for PCs for the comprehensive NIPA revision. This figure is close to the average depreciation rate in column 3 of table $7 \mathrm{~b}$, which was calculated from the regression in which we imposed BEA's price index for PCs. ${ }^{26}$

\footnotetext{
${ }^{25}$ Cummins and Violante (2002) also discussed this difficulty with Lane's depreciation schedule for use in the NIPAs.

${ }^{26}$ The figures in table $7 \mathrm{~b}$ imply an average depreciation rate of 34.6 percent over the first five years of a PC's life; the difference between 34 percent and 34.6 percent reflects assorted small changes to our dataset and specification since we provided BEA with preliminary results. Although our results suggest that depreciation is not geometric, time constraints prevented BEA from considering non-geometric depreciation for this revision of the NIPAs.
} 
NIPA Consumption of Fixed Capital. As indicated in equations 5 and 7, BEA's estimate of the consumption of fixed capital (CFC) for an asset can be calculated as the product of the wealth stock and the depreciation rate for that asset. Our estimate of the depreciation rate for PCs (conditional on BEA's constant-quality price index) is lower than the 39 percent rate that the agency used prior to the December 2003 revision. By itself, the move to a lower rate would reduce BEA's estimate of the CFC for personal computers. However, a rough calculation suggests that this effect is approximately offset by the upward revision to the wealth stock that results from using a lower depreciation rate to construct the stock. Thus, we believe that BEA's switch to a lower depreciation rate implies little change to its estimate of the CFC for personal computers.

\section{User cost of capital}

The user cost of capital in equation 3 depends on an asset's total loss of value in real terms, $\delta^{k}-\left(\pi^{k}-\pi\right)$. Our estimates of $\delta^{k}-\left(\pi^{k}-\pi\right)$ are always in the neighborhood of 50 percent annually, and we would argue that analysts calculating a user cost for PCs for growth accounting or investment analyses ought to use such a figure. For the purpose of constructing the user cost, uncertainty about the precise split between depreciation and real revaluation does not matter.

\section{CONCLUSION}

This paper provides new estimates of depreciation rates for personal computers using an extensive database on used prices. The approach in the paper most closely follows that in Oliner (1993, 1994), and it is very much in the spirit of Hall (1971). Essentially, we regress prices of used PCs (adjusted for the overall GDP price deflator) on a set of performance characteristics, 
flexible functions of time and age, and other controls. After adjusting for retirements - so as to avoid the censoring bias from unobserved prices for retired PCs - the coefficients on the age variables provide estimates of age-related depreciation, while the coefficients on time provide a constant-quality price index for PCs. To map our results into the concepts needed for tax policy and capital measurement, we develop a conceptual framework laying out how depreciation should be measured for these purposes.

Our results show that PCs lose roughly half their remaining value, on average, with each additional year of use. The bulk of that decline reflects the downward revaluation of existing PCs, which is driven by the steep ongoing drop in the constant-quality prices of newly-introduced models. In addition, PCs experience age-related declines in value that stem from the inability of older models to perform the full range of desired tasks and from the decision to retire installed units. We estimate that the resulting depreciation proceeds slowly during the early part of the PC's lifetime but then picks up. In our preferred specification, the depreciation rate averages about 22 percent annually over the first five years of service. However, as we discussed, this figure is sensitive to the estimated rate of constant-quality price change. When we constrain our regression to follow the NIPA constant-quality price series, the depreciation rate increases to an average pace a bit above 34 percent. This estimate of depreciation is suitable for use in the NIPAs, and BEA decided to adopt this geometric approximation in the December 2003 NIPA revision.

Regarding tax policy, our conceptual framework describes the depreciation allowances that would equalize effective tax rates across assets in the face of both general price inflation and changes in relative asset prices. Given this benchmark, our empirical estimates suggest that the 
current tax depreciation schedule for PCs is about right in a zero inflation environment.

However, because the tax code is not indexed for inflation, the tax allowances would be too small in present value for inflation rates above the very low level now prevailing. 


\section{REFERENCES}

Akerlof, George A. (1970). “The Market for 'Lemons': Quality Uncertainty and the Market Mechanism." Quarterly Journal of Economics 84 (August): 488-500.

Auerbach, Alan J. (1982). "Tax Neutrality and the Social Discount Rate: A Suggested Framework." Journal of Public Economics 17 (April): 355-72.

Berndt, Ernst R. and Neal J. Rappaport (2001). "Price and Quality of Desktop and Mobile Personal Computers: A Quarter-Century Historical Overview.” American Economic Review 91 (May): 268-73.

Berndt, Ernst R. and Neal J. Rappaport (2003). "Hedonics for Personal Computers: A Reexamination of Selected Econometric Issues." Mimeo, August 21.

Bloomberg News Service (2003). “U.S. Economy: Computer Replacement Delays May Damp Recovery." May 23.

Bradford, David F. and Don Fullerton (1981). "Pitfalls in the Construction and Use of Effective Tax Rates." In Depreciation, Inflation, and the Taxation of Income from Capital, Charles R. Hulten (ed.). Washington, D.C.: The Urban Institute Press, 251-78.

Bureau of Economic Analysis (1999). Fixed Reproducible Tangible Wealth in the United States, 1925-94. Washington D.C.: U.S. Government Printing Office.

Cartwright, David W. (1986). "Improved Deflation of Purchases of Computers." Survey of Current Business 66 (March): 7-10.

CCH (2002). 2003 U.S. Master Tax Guide. Chicago: CCH Incorporated.

Christensen, Laurits R. and Dale W. Jorgenson (1995). "Measuring Economic Performance in the Private Sector." In Productivity, Volume 1: Postwar U.S. Economic Growth, Dale W. Jorgenson. Cambridge, MA: The MIT Press, 175-272.

Cummins, Jason G. and Giovanni L. Violante (2002). "Investment-Specific Technical Change in the United States (1947-2000): Measurement and Macroeconomic Consequences." Review of Economic Dynamics 5 (April): 243-84.

Diewert, Erwin (2002). "Measuring Capital.” Working paper, April 18. Available at http://www.econ.ubc.ca/diewert/594cap.pdf

Dulberger, Ellen R. (1989). "The Application of a Hedonic Model to a Quality-adjusted Price Index for Computer Processors." In Technology and Capital Formation, Dale W. Jorgenson and Ralph Landau (eds.). Cambridge MA: The MIT Press, 37-75. 
Fraumeni, Barbara M. (1997). "The Measurement of Depreciation in the U.S. National Income and Product Accounts." Survey of Current Business 77 (July): 7-23. Available at http://www.bea.doc.gov/bea/an1.htm

Geske, Michael J., Valerie A. Ramey, and Matthew D. Shapiro (2003). "Why Do Computers Depreciate?" Mimeo, September 2.

Gravelle, Jane G. (1982). "Effects of the 1981 Depreciation Revisions on the Taxation of Income from Business Capital.” National Tax Journal 35 (March): 1-20.

Gravelle, Jane G. (1994). The Economic Effects of Taxing Capital Income. Cambridge, MA: The MIT Press.

Griliches, Zvi (1960). "The Demand for a Durable Input: U.S. Farm Tractors, 1929-57.” In The Demand for Durable Goods, Arnold C. Harberger (ed.). Chicago: University of Chicago Press, 181-207.

Hall, Robert E. (1971). "The Measurement of Quality Change From Vintage Price Data." In Price Indexes and Quality Change: Studies in New Methods of Measurement, Zvi Griliches (ed.). Cambridge, MA: Harvard University Press, 240-71.

Hall, Robert E. and Dale W. Jorgenson (1967). "Tax Policy and Investment Behavior." American Economic Review 57 (June): 391-414.

Hayek, F. A. (1941). “Maintaining Capital Intact: A Reply.” Economica 8 (August): 276-80.

Hicks, J. R. (1942). “Maintaining Capital Intact: A Further Suggestion.” Economica 9 (May): 174-79.

Hill, Peter (1999). "Capital Stocks, Capital Services and Depreciation.” Presented at the meeting of the Canberra Group on Capital Stock Statistics, November 8-10, 1999, Washington D.C. Available at http://www.oecd.org/dataoecd/12/47/2549891.pdf

Hill, Peter (2000). "Economic Depreciation and the SNA." Paper prepared for the $26^{\text {th }}$ General Conference of the International Association for Research in Income and Wealth, August 27-September 2, 2000, Cracow, Poland. Available at http://www.iariw.org/prog2000.htm

Hulten, Charles R. and Frank C. Wykoff (1981a). “The Estimation of Economic Depreciation Using Vintage Asset Prices: An Application of the Box-Cox Power Transformation." Journal of Econometrics 15 (April): 367-96.

Hulten, Charles R. and Frank C. Wykoff (1981b). "The Measurement of Economic Depreciation." In Depreciation, Inflation, and the Taxation of Income from Capital, Charles R. Hulten (ed.). Washington, D.C.: The Urban Institute Press, 81-125. 
Johnson, Norman L., Samuel Kotz, and N. Balakrishnan (1994). Continuous Univariate Distributions, Volume 1. New York: John Wiley \& Sons.

Jorgenson, Dale W. (1974). "The Economic Theory of Replacement and Depreciation.” In Econometrics and Economic Theory: Essays in Honour of Jan Tinbergen, Willy Sellekaerts (ed.). White Plains, NY: International Arts and Sciences Press, 189-221.

Jorgenson, Dale W. (1996). “Empirical Studies of Depreciation.” Economic Inquiry 34 (January): 24-42.

Jorgenson, Dale W. and Martin A. Sullivan (1981). "Inflation and Corporate Capital Recovery." In Depreciation, Inflation, and the Taxation of Income from Capital, Charles R. Hulten (ed.). Washington, D.C.: The Urban Institute Press, 171-237.

Landefeld, J. Steven and Bruce T. Grimm (2000). "A Note on the Impact of Hedonics and Computers on Real GDP." Survey of Current Business 80 (December): 17-22.

Lane, Richard N. (1999). “Appraisal Report 'Large Aerospace Firm' Personal Property,” Los Angeles County, revised February 2, 1999.

OECD (2001). Measuring Capital. OECD Manual: Measurement of Capital Stocks, Consumption of Fixed Capital and Capital Services. Paris: OECD.

Oliner, Stephen D. (1993). "Constant-Quality Price Change, Depreciation, and Retirement of Mainframe Computers.” In Price Measurements and Their Uses, Murray F. Foss, Marilyn E. Manser, and Allan H. Young (eds.). Chicago: University of Chicago Press, $19-61$.

Oliner, Stephen D. (1994). "Measuring Stocks of Computer Peripheral Equipment: Theory and Application." Mimeo.

Pakes, Ariel (2003). “A Reconsideration of Hedonic Price Indices with an Application to PC's." American Economic Review 93 (December): 1578-96.

Pigou, A. C. (1941). "Maintaining Capital Intact.” Economica 8 (August): 271-75.

Richards, Gordon R. (2002). "Nonlinear Technical Advance in the Aggregate Production Function: An Econometric Model.” Intel Corporation. Mimeo.

Sliker, Brian K. (2003). " "Steps Toward Modeling the Distribution of Automobile Retirements." Bureau of Economic Analysis. Mimeo, July 10.

Wykoff, Frank C. (2003). "Obsolescence in Economic Depreciation from the Point of View of the Revaluation Term.” Mimeo, February 28. 


\section{APPENDIX}

This appendix proves two propositions that are cited in section 2 of the text. The first derives the tax depreciation allowances that equalize effective tax rates across assets when one allows for both general price inflation and changes in relative asset prices. This proposition generalizes the well-known result for equalizing effective tax rates in a world with constant relative prices. The second proposition shows how to calculate constant-dollar wealth stocks, again allowing for changes in relative prices.

\section{Proposition 1: Specifying Depreciation Allowances that Equalize Effective Tax Rates}

Let $p_{z, t, a}^{k}$ denote the price of a type- $k$ capital good with the set of embodied characteristics $z$; this price is observed in year $t$ when the capital good is $a$ years old. In addition, let $D T A X_{z, t, a}^{k}$ denote the schedule of tax depreciation allowances for type- $k$ capital goods, let $\theta^{k}$ denote the investment tax credit (ITC) for these goods, let $\tau$ denote the statutory tax rate on corporate profits, and let $\tau^{k, e}$ denote the effective tax rate on the income generated by a type- $k$ capital good (taking account of depreciation allowances and any ITC).

Numerous studies (Jorgenson and Sullivan, 1981, or Gravelle, 1982, for example) have shown that the effective tax rate for every type of capital good will equal the statutory corporate tax rate if the tax allowances for depreciation reflect the asset's actual loss of value and there is no ITC. In the context of our model with changes in relative asset prices, this allowance includes both the age-related loss of value and the revaluation of the asset in real terms. Thus, we show that $\tau^{k, e}=\tau$ for all $k$ if $\theta^{k}=0$ and

$$
\text { (A.1) } D T A X_{z, t, a}^{k}=\left(\delta^{k}-\left(\pi^{k}-\pi\right)\right) p_{z, t, a}^{k}
$$

where $\delta^{k}$ and $\pi^{k}$ are, respectively, the rate of depreciation and the rate of constant-quality price change for type- $k$ capital goods, and $\pi$ is the general rate of inflation. ${ }^{1}$

\section{Proof}

The proof proceeds in three steps. We begin by deriving the expression for the user cost of capital. Next, we express the effective tax rate as a function of the tax parameters and other terms in the user cost. The final step is to show that the effective tax rate equals the statutory tax rate for every type of capital good if $\theta^{k}=0$ and the tax allowance for depreciation accords with equation (A.1).

${ }^{1}$ Gravelle (1982) and others have demonstrated that an investment tax credit of $\theta$ percent for all capital goods reduces the effective tax rate more for short-lived assets than for long-lived assets. One could counteract this effect by granting a progressively larger credit to longer-lived assets, but given our focus on depreciation allowances, we derive the proposition with the ITC set to zero. 


\section{User cost of capital}

Our derivation of the user cost of capital follows the standard method in the literature (see Hall and Jorgenson, 1967, for example). We begin by expressing the current price of the capital good as the discounted value of its future after-tax rental income, plus the present value of its tax allowances for depreciation and any investment tax credit it receives. Let $x^{k}$ denote the present value of the depreciation allowances for type- $k$ capital goods; $x^{k}$ and $\theta^{k}$ are both measured per dollar of the capital good's value. Also, let $c_{z, t, a}^{k}$ denote the pre-tax user cost for type- $k$ capital. In equilibrium, this user cost equals the pre-tax rental income generated by the capital good, allowing its price to be written as

$$
p_{z, t, a}^{k}=\int_{0}^{\infty}(1-\tau) c_{z, t+s, a+s}^{k} e^{-i s} d s+\left(\theta^{k}+\tau x^{k}\right) p_{z, t, a}^{k}
$$

Equation (A.2) adopts the usual assumption that the asset has an infinite service life within a continuous time framework; this set-up simplifies the algebra, while preserving the key economic results. With the asset assumed to depreciate at a constant rate of $\delta^{k}$ percent and to experience constant-quality price change of $\pi^{k}$ percent per period, the user cost (and, hence, the asset's rental income) will decline at a rate of $\left(\delta^{k}-\pi^{k}\right)$ percent. Thus, equation (A.2) can be expressed as

$$
p_{z, t, a}^{k}=\int_{0}^{\infty}(1-\tau) c_{z, t, a}^{k} e^{-\left(\delta^{k}-\pi^{k}\right) s} e^{-i s} d s+\left(\theta^{k}+\tau x^{k}\right) p_{z, t, a}^{k}
$$

Solving (A.3) for $c_{z, t, a}^{k}$ yields

$$
\begin{aligned}
c_{z, t, a}^{k} & =\frac{1-\theta^{k}-\tau x^{k}}{1-\tau} p_{z, t, a}^{k}\left(i+\delta^{k}-\pi^{k}\right) \\
& =\frac{1-\theta^{k}-\tau x^{k}}{1-\tau} p_{z, t, a}^{k}\left[(i-\pi)+\delta^{k}-\left(\pi^{k}-\pi\right)\right],
\end{aligned}
$$

where the expression on the second line adds and subtracts the general rate of inflation $(\pi)$. For the remainder of the derivation, we will use the ratio of the asset's user cost to its price, as shown in equation (A.5):

$$
(c / p)_{z, t, a}^{k}=\frac{1-\theta^{k}-\tau x^{k}}{1-\tau}\left[(i-\pi)+\delta^{k}-\left(\pi^{k}-\pi\right)\right]
$$




\section{Effective tax rate}

The effective tax rate $\left(\tau^{k, e}\right)$ typically has been defined in the literature as the asset's pretax return $\left(\rho^{k}\right)$ minus its after-tax return $\left(r^{k}\right)$, expressed as a percent of its pre-tax return; that is, $\tau^{k, e}=\left(\rho^{k}-r^{k}\right) / \rho^{k}$. Both the pre-tax return and the after-tax return are measured net of depreciation and general price inflation. Abstracting from relative price changes (the standard approach in the tax literature), the real pre-tax return net of depreciation is $\rho^{k}=(c / p)^{k}-\delta^{k}$, where $(c / p)^{k}$ is calculated from equation (A.5) with $\pi^{k}=\pi$. To specify after-tax returns, the usual assumption is that competitive forces equalize the real after-tax return on all assets net of depreciation, so that $r^{k}=i-\pi$.

We generalize this framework to allow for changes in relative asset prices. Only two modifications are required, both affecting the measurement of the pre-tax return. First, we calculate $(c / p)^{k}$ from equation (A.5) without forcing $\pi^{k}$ to equal $\pi$. Second, we subtract both depreciation $\left(\delta^{k}\right)$ and the real revaluation term $\left(\pi^{k}-\pi\right)$ from $(c / p)^{k}$. The intuition is that, with changing relative prices, firms must cover both depreciation and revaluation effects to maintain the real value of their capital stocks. In this general case, the real pre-tax return net of depreciation and revaluation is $\rho^{k}=(c / p)^{k}-\left[\delta^{k}-\left(\pi^{k}-\pi\right)\right]$. Using this expression for $\rho^{k}$ and recalling that $r^{k}=i-\pi$, the effective tax rate can be written as

$$
\begin{gathered}
\tau^{k, e}=\frac{\rho^{k}-r^{k}}{\rho^{k}}=\frac{\left[(c / p)_{z, t, a}^{k}-\left(\delta^{k}-\left(\pi^{k}-\pi\right)\right)\right]-(i-\pi)}{\left[(c / p)_{z, t, a}^{k}-\left(\delta^{k}-\left(\pi^{k}-\pi\right)\right]\right.} \\
=1-\frac{(i-\pi)}{\left[(c / p)_{z, t, a}^{k}-\left(\delta^{k}-\left(\pi^{k}-\pi\right)\right)\right]}
\end{gathered}
$$

Next, substitute the expression for $(c / p)^{k}$ from equation (A.5) into (A.6), which yields

$$
\tau^{k, e}=1-\frac{(1-\tau)(i-\pi)}{\left(1-\theta^{k}-\tau x^{k}\right)\left[(i-\pi)+\delta^{k}-\left(\pi^{k}-\pi\right)\right]-(1-\tau)\left[\delta^{k}-\left(\pi^{k}-\pi\right)\right]}
$$

\section{Equalizing Effective Tax Rates Across Assets}

The final step is to derive the conditions under which the effective tax rate for every type of capital equals the statutory corporate tax rate. We will show that $\tau^{k, e}=\tau$ for all $k$ if $\theta^{k}=0$ and the schedule of tax depreciation allowances matches expression (A.1), which is repeated here as (A.8): 


$$
D T A X_{z, t, a}^{k}=\left(\delta^{k}-\left(\pi^{k}-\pi\right)\right) p_{z, t, a}^{k}
$$

The present value of these allowances per dollar of asset value is

$$
\begin{aligned}
x^{k} & =\int_{0}^{\infty} D T A X_{z, t+s, a+s}^{k} e^{-i s} d s / p_{z, t, a}^{k} \\
& =\int_{0}^{\infty}\left(\delta^{k}-\left(\pi^{k}-\pi\right)\right)\left(p_{z, t+s, a+s}^{k} / p_{z, t, a}^{k}\right) e^{-i s} d s \\
& =\int_{0}^{\infty}\left(\delta^{k}-\left(\pi^{k}-\pi\right)\right) e^{-\left(\delta^{k}-\pi^{k}\right) s} e^{-i s} d s,
\end{aligned}
$$

where the second line substitutes for DTAX from (A.8) and the third line makes use of the assumption that the asset's value declines at a constant rate of $\left(\delta^{k}-\pi^{k}\right)$ percent per period. Equation (A.9) implies that

$$
x^{k}=\frac{\delta^{k}-\left(\pi^{k}-\pi\right)}{i+\delta^{k}-\pi^{k}}=\frac{\delta^{k}-\left(\pi^{k}-\pi\right)}{(i-\pi)+\delta^{k}-\left(\pi^{k}-\pi\right)} .
$$

Finally, substitute the expression for $x^{k}$ from (A.10) and $\theta^{k}=0$ into equation (A.7). After some algebra, the right-hand side of (A.7) reduces to $\tau$, completing the derivation.

\section{Proposition 2: Constructing Constant-dollar Wealth Stocks}

Let $W_{t}^{k}$ and $W_{t}^{k, 1996 \$}$ denote, respectively, the current-dollar and constant-dollar wealth stocks for capital of type $k$. In addition, let $I_{t}^{k}$ and $I_{t}^{k, 1996 \$}$ denote, respectively, current-dollar and constant-dollar investment outlays for this type of capital. Following the NIPA convention at the time we were writing, we assume that constant-dollar series are expressed in 1996 dollars.

We show that the constant-dollar wealth stock can be calculated in two equivalent ways:

$$
W_{t}^{k, 1996 \$}=W_{t}^{k} /\left(1+\pi^{k}\right)^{t-1996}=\sum_{i=0}^{T-1} I_{t-i}^{k, 1996 \$}\left(1-\delta^{k}\right)^{i} .
$$

That is, the constant-dollar wealth stock can be calculated by deflating the current-dollar stock or by constructing an appropriately weighted sum of constant-dollar investment flows. ${ }^{2}$

${ }^{2}$ For this derivation, we shift back to a discrete-time framework and assume that the asset has a finite service life; the discrete-time framework conforms more closely with the actual data on investment and wealth stocks, and there is no algebraic advantage in this case from using continuous time. 


\section{Proof}

To begin, recall that the current-dollar wealth stock for type- $k$ capital equals the sum of current-year investment plus the remaining value of the investment done in previous years:

(A.11) $\quad W_{t}^{k}=\sum_{i=0}^{T-1} I_{t-i}^{k}\left(\left(1+\pi^{k}\right)\left(1-\delta^{k}\right)\right)^{i}$.

Next, multiply and divide the right-hand side of (A.11) by $\left(1+\pi^{k}\right)^{t-i-1996}$ to obtain:

(A.12)

$$
W_{t}^{k}=\sum_{i=0}^{T-1} \frac{I_{t-i}^{k}}{\left(1+\pi^{k}\right)^{t-i-1996}}\left(1+\pi^{k}\right)^{t-i-1996}\left(1+\pi^{k}\right)^{i}\left(1-\delta^{k}\right)^{i}
$$

$$
=\left(1+\pi^{k}\right)^{t-1996} \sum_{i=0}^{T-1} \frac{I_{t-i}^{k}}{\left(1+\pi^{k}\right)^{t-i-1996}}\left(1-\delta^{k}\right)^{i} .
$$

Note that $I_{t-i}^{k} /\left(1+\pi^{k}\right)^{t-i-1996}$ equals the constant-dollar investment done in year $t-i$, which we have denoted by $I_{t-i}^{k, 1996 \$}$. Hence, (A.12) can be written as

$$
W_{t}^{k}=\left(1+\pi^{k}\right)^{t-1996} \sum_{i=0}^{T-1} I_{t-i}^{k, 1996 \$}\left(1-\delta^{k}\right)^{i}
$$

To complete the derivation, note that the constant-dollar wealth stock, $W_{t}^{k, 1996 \$}$, equals the current-dollar stock, $W_{t}^{k}$, divided by the price deflator for year $t,\left(1+\pi^{k}\right)^{t-1996}$. Thus, (A.13) yields:

$$
W_{t}^{k, 1996 \$}=W_{t}^{k} /\left(1+\pi^{k}\right)^{t-1996}=\sum_{i=0}^{T-1} I_{t-i}^{k, 1996 \$}\left(1-\delta^{k}\right)^{i}
$$


Table 1

Alternative Terms in the Literature

\begin{tabular}{||l|l|l||}
\hline \multicolumn{1}{|c|}{ Authors } & \multicolumn{1}{c|}{ Terms for $\delta^{k}$} & \multicolumn{1}{c|}{ Terms for $\delta^{k}-\pi^{k}$} \\
\hline \hline Fraumeni (1997) & Depreciation & Depreciation and revaluation \\
\hline Oliner (1993, 1994) & Partial depreciation & Full depreciation \\
\hline Wykoff (2003) & Economic depreciation & $\begin{array}{l}\text { Economic depreciation and } \\
\text { revaluation }\end{array}$ \\
\hline $\begin{array}{l}\text { Diewert (2002) } \\
\text { Hill (1999, 2000) }\end{array}$ & Cross-section depreciation & Time-series depreciation \\
\hline Hulten and Wykoff (1981a,b) & Economic depreciation & $\begin{array}{l}\text { Economic depreciation and } \\
\text { asset inflation }\end{array}$ \\
\hline
\end{tabular}


Table 2

Example of Tax Deductions for a Personal Computer

(All amounts in dollars, rounded to the nearest cent)

\begin{tabular}{||c|c|c|c|c||}
\hline \hline $\begin{array}{c}\text { Year of } \\
\text { Use }\end{array}$ & $\begin{array}{c}\text { Beginning-of- } \\
\text { year Value } \\
(1)\end{array}$ & $\begin{array}{c}\text { End-of-year } \\
\text { Value } \\
(2)\end{array}$ & $\begin{array}{c}\text { End-of-year Amount } \\
\text { Needed to Maintain } \\
\text { Real Value } \\
(3)\end{array}$ & $\begin{array}{c}\text { Tax Deduction } \\
(4)=(3)-(2)\end{array}$ \\
\hline \hline 1 & 1000.00 & 550.00 & 1050.00 & 500.00 \\
\hline 2 & 550.00 & 302.50 & 577.50 & 275.00 \\
\hline 3 & 302.50 & 166.38 & 317.63 & 151.25 \\
\hline 4 & 166.38 & 91.51 & 174.69 & 83.18 \\
\hline 5 & 91.51 & 50.33 & 96.08 & 45.75 \\
\hline
\end{tabular}

Note: In this example, the PC loses 45 percent of its value each year, while the aggregate price level rises 5 percent annually. We assume that the firm disposes of the PC at the end of year 5 . 
Table 3

Summary of Measurement Results

\begin{tabular}{|c|c|c|}
\hline Concept & Notation & Measurement \\
\hline User Cost of Capital $^{1}$ & $C_{z, t, a}^{k}$ & $p_{z, t, a}^{k}\left[(i-\pi)+\delta^{k}-\left(\pi^{k}-\pi\right)\right]$ \\
\hline $\begin{array}{l}\text { Tax Allowances for } \\
\text { Actual Loss of Value }\end{array}$ & $D T A X_{t}^{k}$ & $p_{z, t, a}^{k}\left[\delta^{k}-\left(\pi^{k}-\pi\right)\right]$ \\
\hline \multicolumn{3}{|l|}{ Wealth Stock } \\
\hline Current dollars & $W_{t}^{k}$ & $\sum_{i=0}^{T-1} I_{t-i}^{k}\left[1-\left(\delta^{k}-\pi^{k}\right)\right]^{i}$ \\
\hline Constant dollars & $W_{t}^{k, 1996 \$}$ & $\sum_{i=0}^{T-1} I_{t-i}^{k, 1996 \$}\left[1-\delta^{k}\right]^{i}$ \\
\hline \multicolumn{3}{|c|}{ NIPA Consumption of Fixed Capital } \\
\hline Current dollars & $C F C_{t}^{k}$ & $W_{t}^{k} \delta^{k}$ \\
\hline Constant dollars & $C F C_{t}^{k, 1996 \$}$ & $W_{t}^{k, 1996 \$} \delta^{k}$ \\
\hline
\end{tabular}

1. We omit the tax parameters in the expression for the user cost to highlight the common elements across the rows of the table. 
Table 4

Timing of Price Observations in Each Bluebook Edition

\begin{tabular}{|c|c|}
\hline Bluebook Edition & Survey Period \\
\hline 1985 & January-June 1985 \\
\hline 1986 & January-June 1986 \\
\hline 1987 & January-June 1987 \\
\hline 1988 & January-June 1988 \\
\hline 1989 & January-June 1989 \\
\hline 1990 & January-June 1990 \\
\hline 1991 & January-June 1991 \\
\hline 1992 & January-June 1992 \\
\hline Fall 1993 & July-September 1993 \\
\hline Fall 1994 & July-September 1994 \\
\hline Winter 1995 & October-December 1994 \\
\hline Winter 1996 & October-December 1995 \\
\hline Winter 1997 & October-December 1996 \\
\hline Winter 1998 & October-December 1997 \\
\hline Winter 1999 & October-December 1998 \\
\hline Winter 2000 & October-December 1999 \\
\hline Winter 2001 & October-December 2000 \\
\hline Winter 2002 & October-December 2001 \\
\hline Winter 2003 & October-December 2002 \\
\hline
\end{tabular}


Table 5

Characteristics of Used PCs by Year Sold

(Mean values shown for price and characteristics)

\begin{tabular}{|c|c|c|c|c|c|c|}
\hline $\begin{array}{l}\text { Year } \\
\text { Sold } \\
\end{array}$ & $\begin{array}{c}\text { Number of } \\
\text { Obs. }\end{array}$ & $\begin{array}{c}\text { Used Price } \\
\text { (dollars) }\end{array}$ & $\begin{array}{c}\text { Model Age } \\
\text { (months) }\end{array}$ & $\begin{array}{c}\text { Size of } \\
\text { Hard Disk } \\
(\mathrm{Mb})\end{array}$ & $\begin{array}{c}\text { CPU } \\
\text { Speed } \\
(\mathrm{Mhz}) \\
\end{array}$ & $\begin{array}{c}\text { Amount of } \\
\text { RAM } \\
(\mathrm{Mb})\end{array}$ \\
\hline 1985 & 4 & 2439.0 & 12.0 & 12.5 & 6.1 & 0.6 \\
\hline 1986 & 6 & 2661.2 & 25.0 & 15.0 & 6.9 & 0.5 \\
\hline 1987 & 18 & 2549.7 & 29.0 & 31.1 & 8.9 & 0.7 \\
\hline 1988 & 36 & 3084.0 & 32.3 & 33.4 & 9.0 & 0.8 \\
\hline 1989 & 77 & 2154.9 & 38.0 & 45.9 & 10.1 & 0.8 \\
\hline 1990 & 175 & 1980.4 & 28.0 & 89.8 & 15.7 & 1.3 \\
\hline 1991 & 250 & 2094.0 & 34.3 & 106.7 & 17.2 & 1.6 \\
\hline 1992 & 312 & 1213.5 & 39.2 & 110.3 & 18.6 & 1.8 \\
\hline 1993 & 478 & 642.1 & 41.8 & 167.7 & 25.0 & 2.8 \\
\hline 1994 & 1368 & 567.9 & 42.4 & 316.7 & 31.1 & 4.7 \\
\hline 1995 & 970 & 473.2 & 44.5 & 366.8 & 42.1 & 5.8 \\
\hline 1996 & 1191 & 471.0 & 43.8 & 598.4 & 60.4 & 8.3 \\
\hline 1997 & 1319 & 346.0 & 49.0 & 920.9 & 76.9 & 11.0 \\
\hline 1998 & 1445 & 299.3 & 43.3 & 2063.8 & 131.1 & 21.9 \\
\hline 1999 & 1548 & 242.0 & 43.2 & 3911.6 & 197.5 & 36.4 \\
\hline 2000 & 1818 & 335.7 & 45.9 & 6411.5 & 276.4 & 50.2 \\
\hline 2001 & 970 & 289.5 & 33.9 & 11139.1 & 476.6 & 80.7 \\
\hline 2002 & 911 & 272.9 & 40.5 & 14046.2 & 579.6 & 96.3 \\
\hline
\end{tabular}


Table 6

\section{Regression Results}

(Dependent variable is natural log of used PC price divided by GDP chain-weight price index; standard errors in parentheses)

\begin{tabular}{|c|c|c|c|c|c|}
\hline Variable & Baseline & $\begin{array}{l}\text { Imposed } \\
\text { PC price }\end{array}$ & Variable & Baseline & $\begin{array}{l}\text { Imposed } \\
\text { PC price }\end{array}$ \\
\hline Constant & $\begin{array}{l}2.045 \\
(.174)\end{array}$ & $\begin{array}{l}5.234 \\
(.045)\end{array}$ & Mar. 1988 dummy & $\begin{array}{l}-.251 \\
(.183)\end{array}$ & \\
\hline Ln MHZ & $\begin{array}{c}.463 \\
(.013)\end{array}$ & $\begin{array}{l}-.039 \\
(.013)\end{array}$ & Mar. 1989 dummy & $\begin{array}{l}-.578 \\
(.176)\end{array}$ & \\
\hline Ln RAM & $\begin{array}{l}.393 \\
(.009)\end{array}$ & $\begin{array}{l}.308 \\
(.012)\end{array}$ & Mar. 1990 dummy & $\begin{array}{r}-1.225 \\
(.173)\end{array}$ & \\
\hline Ln HD & $\begin{array}{l}.174 \\
(.007)\end{array}$ & $\begin{array}{l}.147 \\
(.009)\end{array}$ & Mar. 1991 dummy & $\begin{array}{r}-1.494 \\
(.172)\end{array}$ & \\
\hline Monitor dummy & $\begin{array}{l}.182 \\
(.009)\end{array}$ & $\begin{array}{l}.227 \\
(.011)\end{array}$ & Mar. 1992 dummy & $\begin{array}{r}-2.097 \\
(.172)\end{array}$ & \\
\hline CD-ROM dummy & $\begin{array}{l}.093 \\
(.012)\end{array}$ & $\begin{array}{l}.105 \\
(.015)\end{array}$ & Aug. 1993 dummy & $\begin{array}{r}-3.073 \\
(.171)\end{array}$ & \\
\hline FAST chip dummy & $\begin{array}{l}.014 \\
(.018)\end{array}$ & $\begin{array}{l}.268 \\
(.021)\end{array}$ & Aug. 1994 dummy & $\begin{array}{r}-3.278 \\
(.171)\end{array}$ & \\
\hline Compaq dummy & $\begin{array}{l}-.027 \\
(.010)\end{array}$ & $\begin{array}{l}-.065 \\
(.013)\end{array}$ & Nov. 1994 dummy & $\begin{array}{c}-3.422 \\
(.171)\end{array}$ & \\
\hline IBM dummy & $\begin{array}{l}.102 \\
(.012)\end{array}$ & $\begin{array}{l}.040 \\
(.014)\end{array}$ & Nov. 1995 dummy & $\begin{array}{r}-3.846 \\
(.171)\end{array}$ & \\
\hline Packard Bell dummy & $\begin{array}{l}-.269 \\
(.018)\end{array}$ & $\begin{array}{l}-.437 \\
(.022)\end{array}$ & Nov. 1996 dummy & $\begin{array}{r}-4.173 \\
(.172)\end{array}$ & \\
\hline Model age & $\begin{array}{c}.495 \\
(.208)\end{array}$ & $\begin{array}{c}.425 \\
(.254)\end{array}$ & Nov. 1997 dummy & $\begin{array}{r}-4.721 \\
(.172)\end{array}$ & \\
\hline$(\text { Model age })^{2}$ & $\begin{array}{r}-5.362 \\
(.650)\end{array}$ & $\begin{array}{r}-9.836 \\
(.800)\end{array}$ & Nov. 1998 dummy & $\begin{array}{r}-5.987 \\
(.173)\end{array}$ & \\
\hline$(\text { Model age })^{3}$ & $\begin{array}{l}6.979 \\
(.767)\end{array}$ & $\begin{array}{r}11.354 \\
(.948)\end{array}$ & Nov. 1999 dummy & $\begin{array}{r}-6.784 \\
(.174)\end{array}$ & \\
\hline$(\text { Model age) })^{4}$ & $\begin{array}{c}-2.753 \\
(.298)\end{array}$ & $\begin{array}{r}-3.918 \\
(.370)\end{array}$ & Nov. 2000 dummy & $\begin{array}{r}-6.777 \\
(.175)\end{array}$ & \\
\hline Mar. 1985 dummy & $\begin{array}{l}-.126 \\
(.268)\end{array}$ & & Nov. 2001 dummy & $\begin{array}{r}-7.620 \\
(.176)\end{array}$ & \\
\hline Mar. 1986 dummy & $\begin{array}{c}0 \\
\text { (omitted) }\end{array}$ & & Nov. 2002 dummy & $\begin{array}{r}-7.774 \\
(.177)\end{array}$ & \\
\hline Mar. 1987 dummy & $\begin{array}{l}-.324 \\
(.195)\end{array}$ & & & & \\
\hline Adjusted $\mathrm{R}^{2}$ & .92 & .84 & No. of observations & 12,896 & 12,896 \\
\hline
\end{tabular}


Table 7a

Price Profiles and Survival Probabilities for Personal Computers: Baseline Regression

\begin{tabular}{|c|c|c|c|c|c|c|c|}
\hline \multirow[b]{2}{*}{$\begin{array}{l}\text { Model Age } \\
\text { (months) }\end{array}$} & \multirow{2}{*}{$\begin{array}{c}\text { Age-Price } \\
\text { Profile } \\
(1) \\
\end{array}$} & \multirow{2}{*}{$\begin{array}{c}\text { Survival } \\
\text { Probability } \\
(2) \\
\end{array}$} & \multirow{2}{*}{$\begin{array}{l}\text { Survival-Adj. } \\
\text { Age-Price } \\
\text { Profile } \\
(3)=(2)^{*}(1) \\
\end{array}$} & \multirow{2}{*}{$\begin{array}{c}\text { Real } \\
\text { Revaluation } \\
(4)\end{array}$} & \multicolumn{3}{|c|}{ Total Effect on Price } \\
\hline & & & & & $\begin{array}{l}\text { No Inflation } \\
(5)=(4) *(3) \\
\end{array}$ & $\begin{array}{c}1 \% \text { Inflation } \\
(6)\end{array}$ & $\begin{array}{c}4 \% \text { Inflation } \\
(7)\end{array}$ \\
\hline 0 & 100.0 & 100.0 & 100.0 & 100.0 & 100.0 & 100.0 & 100.0 \\
\hline 6 & 101.2 & 99.2 & 100.4 & 80.5 & 80.9 & 81.5 & 83.3 \\
\hline 12 & 99.4 & 96.9 & 96.3 & 64.9 & 62.5 & 63.4 & 66.3 \\
\hline 18 & 95.4 & 93.2 & 88.9 & 52.2 & 46.4 & 47.5 & 50.8 \\
\hline 24 & 90.2 & 88.2 & 79.6 & 42.1 & 33.5 & 34.5 & 37.7 \\
\hline 30 & 84.5 & 82.2 & 69.5 & 33.9 & 23.5 & 24.5 & 27.3 \\
\hline 36 & 78.9 & 75.4 & 59.5 & 27.3 & 16.2 & 17.0 & 19.4 \\
\hline 42 & 73.6 & 68.1 & 50.1 & 22.0 & 11.0 & 11.6 & 13.6 \\
\hline 48 & 68.9 & 60.6 & 41.7 & 17.7 & 7.4 & 7.9 & 9.4 \\
\hline 54 & 65.0 & 53.0 & 34.5 & 14.3 & 4.9 & 5.3 & 6.4 \\
\hline 60 & 61.7 & 45.7 & 28.2 & 11.5 & 3.2 & 3.5 & 4.4 \\
\hline 66 & 59.2 & 38.8 & 23.0 & 9.2 & 2.1 & 2.3 & 2.9 \\
\hline 72 & 57.2 & 32.4 & 18.5 & 7.4 & 1.4 & 1.5 & 2.0 \\
\hline 78 & 55.8 & 26.6 & 14.9 & 6.0 & 0.9 & 1.0 & 1.3 \\
\hline
\end{tabular}


Table 7b

Price Profiles and Survival Probabilities for Personal Computers: Imposed PC Prices

\begin{tabular}{|c|c|c|c|c|c|c|c|}
\hline \multirow[b]{2}{*}{$\begin{array}{c}\text { Model Age } \\
\text { (months) }\end{array}$} & \multirow{2}{*}{$\begin{array}{c}\text { Age-Price } \\
\text { Profile } \\
(1) \\
\end{array}$} & \multirow{2}{*}{$\begin{array}{c}\text { Survival } \\
\text { Probability } \\
(2) \\
\end{array}$} & \multirow{2}{*}{$\begin{array}{l}\text { Survival-Adj. } \\
\text { Age-Price } \\
\text { Profile } \\
(3)=(2)^{*}(1) \\
\end{array}$} & \multirow{2}{*}{$\begin{array}{c}\text { Real } \\
\text { Revaluation } \\
(4)\end{array}$} & \multicolumn{3}{|c|}{ Total Effect on Price } \\
\hline & & & & & $\begin{array}{l}\text { No Inflation } \\
(5)=(4) *(3) \\
\end{array}$ & $\begin{array}{c}1 \% \text { Inflation } \\
(6)\end{array}$ & $\begin{array}{c}\text { 4\% Inflation } \\
(7)\end{array}$ \\
\hline 0 & 100.0 & 100.0 & 100.0 & 100.0 & 100.0 & 100.0 & 100.0 \\
\hline 6 & 99.3 & 99.2 & 98.5 & 87.2 & 85.9 & 86.5 & 88.2 \\
\hline 12 & 93.1 & 96.9 & 90.2 & 76.1 & 68.7 & 69.6 & 72.3 \\
\hline 18 & 83.5 & 93.2 & 77.8 & 66.4 & 51.6 & 52.7 & 55.8 \\
\hline 24 & 72.6 & 88.2 & 64.0 & 57.9 & 37.1 & 38.1 & 41.1 \\
\hline 30 & 61.7 & 82.2 & 50.7 & 50.5 & 25.6 & 26.5 & 29.1 \\
\hline 36 & 51.8 & 75.4 & 39.1 & 44.1 & 17.2 & 17.9 & 20.1 \\
\hline 42 & 43.3 & 68.1 & 29.5 & 38.4 & 11.3 & 11.9 & 13.6 \\
\hline 48 & 36.3 & 60.6 & 22.0 & 33.5 & 7.4 & 7.8 & 9.0 \\
\hline 54 & 30.6 & 53.0 & 16.2 & 29.2 & 4.7 & 5.0 & 6.0 \\
\hline 60 & 26.2 & 45.7 & 12.0 & 25.5 & 3.1 & 3.3 & 3.9 \\
\hline 66 & 22.7 & 38.8 & 8.8 & 22.2 & 2.0 & 2.1 & 2.6 \\
\hline 72 & 20.0 & 32.4 & 6.5 & 19.4 & 1.3 & 1.4 & 1.7 \\
\hline 78 & 18.0 & 26.6 & 4.8 & 16.9 & 0.8 & 0.9 & 1.1 \\
\hline
\end{tabular}


Table 8

Alternative Estimates of Price Declines for Personal Computers

(All figures at annual rates)

\begin{tabular}{|c|c|c|c|c|c|}
\hline & $\begin{array}{c}\text { Sample } \\
\text { period } \\
(1) \\
\end{array}$ & $\begin{array}{c}\text { Total price } \\
\text { decline } \\
(2) \\
\end{array}$ & $\begin{array}{c}\text { Depreciation } \\
\text { (3) } \\
\end{array}$ & $\begin{array}{c}\text { Revaluation } \\
\text { (4) } \\
\end{array}$ & $\begin{array}{c}\text { Cross- } \\
\text { product } \\
(5) \\
\end{array}$ \\
\hline \multicolumn{6}{|l|}{ This paper } \\
\hline 1. Baseline specification & $1985-2002$ & 47.8 & 22.4 & 32.7 & -7.3 \\
\hline 2. Imposing BEA PC prices & $1985-2002$ & 48.7 & 34.6 & 21.5 & -7.4 \\
\hline 3. Adding CPU dummies & $1985-2002$ & 46.9 & 18.7 & 34.7 & -6.5 \\
\hline 4. Allowing time-varying effects of characteristics & $1985-2002$ & 49.2 & 22.4 & 34.6 & -7.8 \\
\hline 5. Using wholesale average-condition prices & $1985-2002$ & 47.5 & 24.2 & 30.7 & -7.4 \\
\hline 6. Baseline specification, shorter sample & $1990-2000$ & 51.9 & 21.6 & 38.7 & -8.4 \\
\hline \multicolumn{6}{|l|}{ Geske, Ramey, Shapiro (2003) } \\
\hline 7. Unconstrained & $1990-2000$ & 49.8 & 27.3 & 30.9 & -8.4 \\
\hline 8. Imposing BEA computer prices & $1990-2000$ & 50.3 & 41.1 & 15.7 & -6.5 \\
\hline
\end{tabular}

Note. Revaluation is shown here as a rate of decline, and thus without the negative sign that appears elsewhere in the paper. 
Table 9

Tax Depreciation Schedules for Personal Computers

(Percent of initial value)

\begin{tabular}{|c|c|c|c|c|c|}
\hline \multirow[b]{2}{*}{ Year } & \multirow[b]{2}{*}{$\begin{array}{c}\text { Current Law } \\
\text { (1) }\end{array}$} & \multirow{2}{*}{$\begin{array}{l}\text { Current Law, } \\
\text { Adjusted for } \\
\text { Retirements } \\
\text { (2) }\end{array}$} & \multicolumn{3}{|c|}{ Covering Full Loss of Value } \\
\hline & & & $\begin{array}{c}\pi=0 \% \\
(3)\end{array}$ & $\begin{array}{c}\pi=1 \% \\
(4)\end{array}$ & $\begin{array}{c}\pi=4 \% \\
(5)\end{array}$ \\
\hline 1 & 20.0 & 20.6 & 19.1 & 19.1 & 19.1 \\
\hline 2 & 32.0 & 34.6 & 34.4 & 34.7 & 35.5 \\
\hline 3 & 19.2 & 21.1 & 22.9 & 23.4 & 25.1 \\
\hline 4 & 11.5 & 11.9 & 12.5 & 13.0 & 14.5 \\
\hline 5 & 11.5 & 8.7 & 6.1 & 6.4 & 7.5 \\
\hline 6 & 5.8 & 3.1 & 2.8 & 3.0 & 3.7 \\
\hline 7 & 0.0 & 0.0 & 2.1 & 2.3 & 3.0 \\
\hline $\mathrm{PDV}, \pi=0 \%$ & 92.5 & 93.0 & 92.9 & & \\
\hline $\mathrm{PDV}, \pi=1 \%$ & 90.6 & 91.2 & & 92.7 & \\
\hline $\mathrm{PDV}, \pi=4 \%$ & 85.2 & 86.1 & & & 92.3 \\
\hline
\end{tabular}

Note. The figures in the table are based on the assumption that the PC is installed in the middle of the year. Given this half-year convention, the entries for year 1 show the depreciation over the first six months of the PC's life, the entries for year 2 show the depreciation between six and 18 months, and so on. 
Figure 1

Number of Price Observations by Model Age in Years

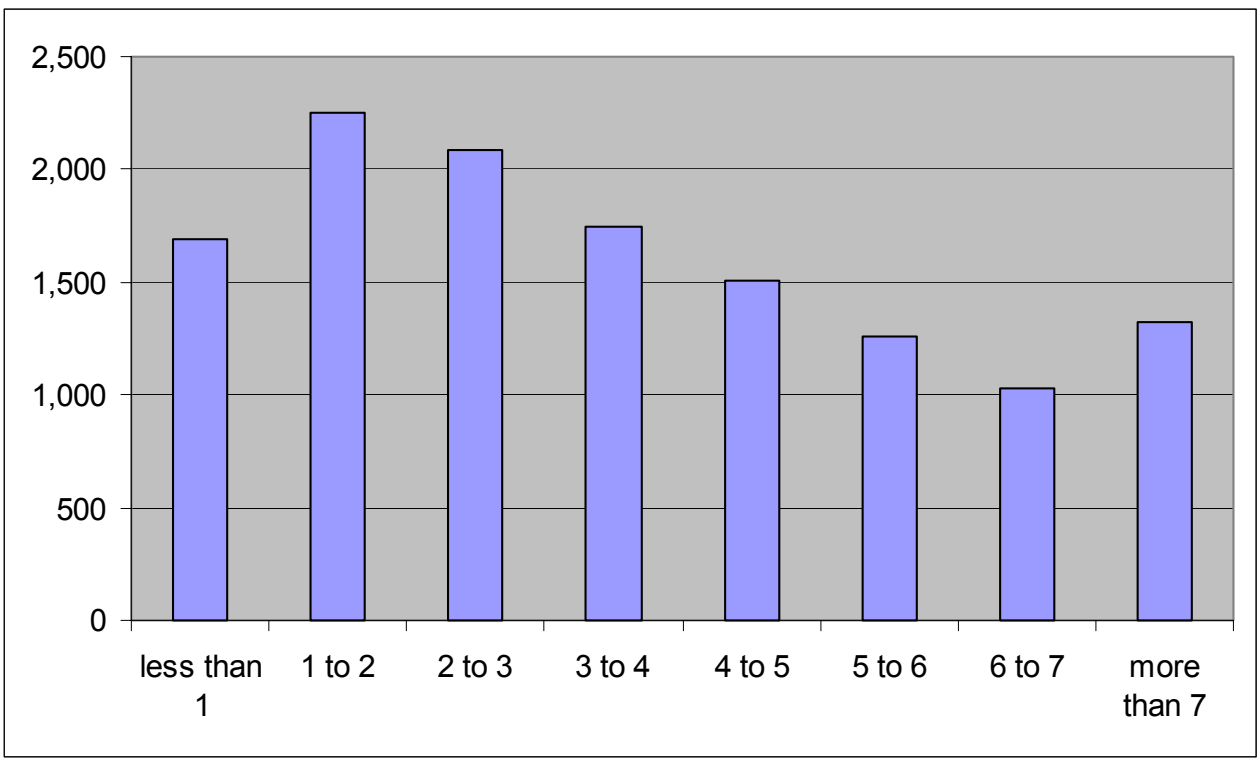

